\title{
Thioperamide Alleviates Lipopolysaccharide- Induced Neuroinflammation and Promotes Neurogenesis by Histamine Dependent Activation of H2R/PKA/CREB Pathway
}

\section{Jiangong Wang}

Binzhou Medical University Hospital

Bin Liu

binzhou medical university hospital

Fengjiao Sun

Binzhou Medical University Hospital

\section{Yong Xu}

Binzhou Medical University

\section{Dongmei Zhao}

Binzhou Medical University

Haiyun Luan

Binzhou Medical University

\section{Meizi Yang}

Binzhou Medical University

\section{Chaoyun Wang}

Binzhou Medical University

\section{Wentao Wang}

Binzhou Medical University Hospital

\section{Dunjiang Liu}

Binzhou Medical University

\section{Linshan Sun}

Binzhou Medical University Hospital

Haijing Yan ( $\square$ hjyan211@163.com )

Binzhou Medical University https://orcid.org/0000-0002-0997-5299

\section{Research}

Keywords: Histamine, H3R antagonist, H2R, Thioperamide, Aging, Cognitive impairment, Microglia, M1, M2, Neuroinflammation, neurogenesis, CREB, NF-KB, IL-1 $\beta$, IL-6, TNFa, IL-4, IL-10, BDNF 
Posted Date: November 2nd, 2021

DOI: https://doi.org/10.21203/rs.3.rs-1003030/v1

License: (c) (i) This work is licensed under a Creative Commons Attribution 4.0 International License. Read Full License 


\section{Abstract \\ Background}

Adult neurogenesis in hippocampus dentate gyrus (DG) is associated with numerous neurodegenerative diseases such as aging and Alzheimer's disease (AD). Overactivation of microglia induced neuroinflammation is well acknowledged to contribute to the impaired neurogenesis in pathologies of these diseases and then leading to cognitive dysfunction. Histamine $\mathrm{H} 3$ receptor $(\mathrm{H} 3 \mathrm{R})$ is a presynaptic autoreceptor regulating histamine release via negative feedback way. Recently, studies show that H3R are highly expressed not only in neurons but also in microglia to modulate inflammatory response. However, whether inhibition of H3R is responsible for the neurogenesis and cognition in chronic neuroinflammation induced injury and the mechanism remains unclear.

\section{Methods}

Microglia activity, inflammation and neurogenesis were assessed in vivo by using lipopolysaccharide (LPS) induced model of inflammation. Mice were treated with thioperamide, pyrilamine or cimetidine to evaluate the effect of thioperamide on inflammation and the involving role of histamine. Protein levels of PKA/CREB and NF-KB were assessed to investigate the mechanism by which thioperamide regulate inflammatory response and neurogenesis. The cognitive function was tested by novel object recognition, $Y$ maze and morris water maze.

\section{Results}

In this study, we found that inhibition of H3R by thioperamide reduced the microglia activity and promoted a phenotypical switch from pro-inflammatory M1 to anti-inflammatory M2 in microglia, and ultimately attenuated LPS induced neuroinflammation in mice. Additionally, thioperamide rescued the neuroinflammation induced impairments of neurogenesis and cognitive function. Mechanically, the neuroprotection of thioperamide was involved in histamine dependent $\mathrm{H} 2$ receptor $(\mathrm{H} 2 \mathrm{R})$ activation, because cimetidine, an H2R antagonist but not pyrilamine, an H1R antagonist reversed the above effects of thioperamide. Moreover, thioperamide activated the $\mathrm{H} 2 \mathrm{R}$ downstream phosphorylated protein kinase $\mathrm{A}$ (PKA)/cyclic AMP response element-binding protein (CREB) pathway but inhibited nuclear factor kappa-B (NF-KB) signaling. Activation of CREB by thioperamide promoted interaction of CREB-CREB Binding Protein (CBP) to increase anti-inflammatory cytokines (Interleukin-4 and Interleukin-10) and brain-derived neurotrophic factor (BDNF) release but inhibited NF-KB-CBP interaction to decrease pro-inflammatory cytokines (Interleukin-1 $\beta$, Interleukin-6 and Tumor necrosis factor $\alpha$ ) release. H89, an inhibitor of PKA/CREB signaling, abolished effects of thioperamide on neuroinflammation and neurogenesis.

\section{Conclusions}


Taken together, these results suggested under LPS induced neuroinflammation, the H3R antagonist thioperamide inhibited microglia activity and inflammatory response, and ameliorated impairment of neurogenesis and cognitive dysfunction via enhancing histamine release. Histamine activated $\mathrm{H} 2 \mathrm{R}$ and reinforced CREB-CBP interaction but weakened NF-KB-CBP interaction to exert anti-inflammatory effects. This study uncovered a novel histamine dependent mechanism behind the therapeutic effect of thioperamide on neuroinflammation.

\section{Background}

Adult neurogenesis, a process of generating functional neurons from adult neural precursors, occurs throughout life in restricted brain regions in mammals [1, 2]. Within the hippocampal dentate gyrus (DG), newly born neurons in the granule cell layer (GL) send axonal projections to the CA3 subfield of the hippocampus and spineless dendrites to the molecular layer [3]. The new neurons then integrate into the existing hippocampal tri-synaptic circuitry by establishing synapses in the molecular layer with other neurons,[4] and then promote the ability of learning and memory [5]. Dysregulation of hippocampal neurogenesis has been shown to be an important mechanism underlying the cognitive impairment associated with normal aging, as well as the cognitive deficits in Alzheimer's disease (AD) and other neurodegenerative diseases [6]. Chronic neuroinflammation is a common pathological feature in normal aging as well as in these neurodegenerative conditions and has been shown to negatively affect hippocampal neurogenesis and cognitive processes across the lifespan [7]. Conversely, neurotrophic factors, environmental enrichment, learning, and exercise could positively regulate adult hippocampal neurogenesis and associated cognitive function $[6,8,9]$. Therefore, clarify the fundamental mechanisms regulating adult neurogenesis in physiological and pathological conditions will thus provide the basis for cell replacement therapy for treatment of disorders of central nervous system (CNS).

Microglia account for approximately $10 \%$ of cells in the CNS, and help shape neural circuits by modulating the strength of synaptic transmissions and sculpting neuronal synapses [10]. Overactivation of glial cells is commonly found in numerous neurodegenerative diseases such as normal aging and $A D$ in CNS $[11,12]$. Microglia activation is often categorized as either classical (M1) or alternative (M2). M1 microglia produce proinflammatory cytokines and chemokines, such as interleukin-1 $\beta$ (IL-1 $\beta$ ), interleukin6 (IL-6) and tumor necrosis factor a (TNFa) whereas M2 microglia produce anti-inflammatory cytokines such as interleukin-4 (IL-4), interleukin-10 (IL-10) and neurotrophic factors such as brain-derived neurotrophic factor (BDNF) and insulin-like growth factor-1(IGF-1) [13]. Recent studies show that microglia are involved in neurogenesis [14]. IL4-driven M2 microglia polarization in the hippocampus trigger BDNF-dependent neurogenesis [15]. However, mediators of M1 microglia, including IL-1 $\beta$, IL-6 and TNF-a have been shown to have a negative effect on hippocampal neurogenesis by reducing the proliferation and survival of newborn cells $[6,16,17]$. Thus, it is of great importance to study focusing on therapeutic agents capable of inducing M2 or preventing M1 polarization in chronic neurodegenerative diseases. 
Histamine is a heterocyclic amine formed by decarboxylation of the amino acid l-histidine. It is involved in the local regulation of physiological processes but also can occur exogenously in the food supply [18]. In the CNS, histamine is an endogenous neurotransmitter regulating many physiological processes including temperature regulation, emesis, food intake, and avoidance behavior [19, 20]. Accumulating evidence suggests that the activating histaminergic system in CNS may regulate brain injury [21, 22]. However, the direct application of histamine is clinically limited due to its poor penetration of the bloodbrain barrier and its pro-inflammatory effect in the peripheral system [22]. Histamine H3 receptor (H3R) is a presynaptic autoreceptor that regulates histamine release from histaminergic neurons via negative feedback way [23,24], as well as a heteroreceptor that regulates the release of other neurotransmitters [25-30]. A number of experiments have also provided evidences that inhibition of H3R could alleviate cognitive deficit in chronic inflammation related neurodegenerative diseases such as normal aging and $A D$ [31-37]. H3R antagonist rescues autistic spectrum disorder-like behaviors through attenuating the proinflammatory cytokines [38]. Thioperamide, a histamine H3R antagonist, also suppresses inflammatory cell recruitment through histamine dependent mechanism [39]. Recent studies indicate that histamine and $\mathrm{H} 3 \mathrm{R}$ are also involved in modulation of neurogenesis. Histamine enhances neurogenesis, and promotes neuronal differentiation and dendritic arbor complexity [40, 41]. Inhibition of H3R promotes neurogenesis in preterm white matter injury, traumatic brain injury and aging mice [36, 42-44]. Moreover, $\mathrm{H} 3 \mathrm{R}$ is also involved in migration of neural stem cells (NSCs) [45]. Therefore, H3R antagonist may serve to develop new therapeutic approaches to overcome chronic inflammation related neurodegenerative disorders. However, the mechanism underlying the anti-inflammatory effect of H3R antagonist on microglial phenotypes and its effect on inflammation-related impairment of neurogenesis has not been reported.

In this study, we hypothesized that thioperamide, a H3R antagonist has a microglia-dependent antiinflammatory effect, which is involved with neurogenesis. We investigated the effects of thioperamide on microglial phenotypes and hippocampal neurogenesis in LPS-induced inflammation in mice. We found that thioperamide inhibited inflammation and promoted neurogenesis through histamine-dependent H2R/cAMP/PKA/CREB pathway. Furthermore, this study showed that thioperamide promoted secretion of anti-inflammatory cytokines including IL-4, IL-10 and BDNF from M2 microglia via enhancing CREBCREB binding protein (CBP) interaction but inhibited secretion of pro-inflammatory cytokines IL-1 $\beta$, IL-6 and TNFa from M1 microglia via suppressing CREB- nuclear factor kappa-B (NF-KB) interaction. We would uncover a novel mechanism that H3R antagonist-mediated neurogenesis in chronic inflammation related neurodegenerative diseases.

\section{Methods}

\section{Ethical statement}

All animal studies were carried out according to protocols approved by the Institutional Animal Care and Use Committee of Binzhou Medical University Hospital, and conducted in compliance with the National 
Institutes of Health Guide for the Care and Use of Laboratory Animals. Efforts were made to minimize any pain or discomfort, and the minimum number of animals was used.

\section{Animals}

Adult male C57BL/ 6 mice (Pengyue Laboratory, Jinan, China) weighing 22-25g were used in this study. The mice were housed in a temperature- and humidity-controlled animal facility, which was maintained on a $12 \mathrm{~h}$ light/dark cycle, food and water were given ad libitum.

\section{Stereotaxic surgery}

Stereotaxic surgery was performed as previously described [46] . Mice were anesthetized with the intraperitoneal injection of $1 \%$ chloral hydrate and then immobilized on a stereotactic frame. The gauge guide cannula was implanted into the lateral ventricle $(0.2 \mathrm{~mm}$ posterior, $1.1 \mathrm{~mm}$ lateral and $2.7 \mathrm{~mm}$ ventral to the bregma). After surgery, mice were housed individually and allowed to recover for $7 \mathrm{~d}$.

\section{Drug treatments}

For in vivo study, a stainless-steel injector connected to a 5-ml syringe was inserted into the guide cannula and extended $1 \mathrm{~mm}$ beyond the tip. The administration of the chemicals was administrated on the basis of previous studies [47] . LPS (i.p., $1 \mathrm{mg} / \mathrm{kg}$ ) or vehicle was administrated daily at 7 days after stereotaxic surgery for 5 days. Thioperamide (i.p., $5 \mathrm{mg} / \mathrm{kg}$ ) or vehicle was administrated daily at 7 days after stereotaxic surgery until the beginning of the behavior tests on day 14 . $\mathrm{H} 89$ or vehicle (i.c.v., $2 \mu \mathrm{g}$ of $2 \mu \mathrm{l}$ ) was administrated $0.5 \mathrm{~h}$ before thioperamide injection. 5-bromo-2'-deoxyuridine (BrdU) (i.p., $50 \mathrm{mg} / \mathrm{kg}$ ) was administrated for 4 times every $4 \mathrm{~h}$ at 7 days after stereotaxic surgery, and then administrated every other day before the behavior experiments [48] . At 14 days after stereotaxic surgery, the novel object recognition (NOR) test was carried on for 4 days. At 18 days after stereotaxic surgery, $Y$ maze (YM) test was carried on for 1 day. At 19 days after stereotaxic surgery, morris water maze (MWM) test was carried on for 6 days. During the period of behavior test, thioperamide or vehicle was administrated $0.5 \mathrm{~h}$, whereas $\mathrm{H} 89$ or vehicle was administrated $1 \mathrm{~h}$ before the test at day 14 , day 18 and day 19.

\section{Immunohistochemistry}

Immunostaining was performed in frozen brain sections. Frozen brain sections were fixed in $4 \%$ paraformaldehyde for $2 \mathrm{~h}$, and then incubated in $5 \%$ bovine serum albumin (BSA, Solarbio) for $2 \mathrm{~h}$ to block nonspecific binding of IgG. Then the cells were reacted with goat antibody against lba1 (Abcam, 1:300), mouse antibody against NeuN (Millipore, 1:300), MAP2 (Millipore, 1:300) and rabbit monoclonal antibody against DCX (Cell Signaling Technology, 1:100). After repeated washes in PBS buffer, cells were incubated with secondary antibody in $3 \% \mathrm{BSA}$ for $2 \mathrm{~h}$ at $25^{\circ} \mathrm{C}$. The secondary antibodies used in this experiment were donkey anti-mouse IgG-AlexaFluo 488 (1:300, 21202, Invitrogen), goat antirabbit IgG-AlexaFluo 546 (Invitrogen, 1:300), goat anti-rabbit IgG-AlexaFluo 647 (Invitrogen, 1:300), goat anti-mouse IgG-AlexaFluo 647 (Invitrogen, 1:300), donkey anti-rabbit IgG-AlexaFluo 488 (Invitrogen, 
1:300), goat anti-mouse IgG-AlexaFluo 546 (Invitrogen, 1:300), and donkey anti-goat IgG-AlexaFluo 546 (Invitrogen, 1:300). After further washing in PBS, cultures were dried, cover slipped and mounted on glass slides. All the immunohistochemical data represent mean values of 5 brain sections per mouse. The area coverage as well as the number of Iba1-positive, DCX-positive cells were quantified using ImageJ.

\section{BrdU/DCX/NeuN staining}

BrdU was used to label newly born cells, DCX was used to label immature neurons and NeuN was used to label mature neurons. The frozen brain sections $(40 \mu \mathrm{m})$ were incubated for $30 \mathrm{~min}$ in $2 \mathrm{~N} \mathrm{HCl}$ at $37^{\circ} \mathrm{C}$, and neutralized with $0.1 \mathrm{M}$ borate buffer (Sinopharm Chemical Reagent, $\mathrm{PH}=8.5$ ) for $10 \mathrm{~min}$. After incubating in $1 \% \mathrm{H} 2 \mathrm{O} 2(30 \% \mathrm{H} 1009$, Sigma) for 10 min, the sections were blocked with PBS containing $1 \% \mathrm{BSA}$ and $0.3 \%(\mathrm{w} / \mathrm{v})$ Triton $\mathrm{X}-100(\mathrm{~T} 8787$, Sigma) for $1 \mathrm{~h}$ at room temperature. They were then reacted with rat monoclonal anti-BrdU (1:50, Abcam), rabbit monoclonal anti-DCX (1:50, Cell Signaling Technology) and mouse monoclonal antibody against NeuN (1:300, Millipore) at $4^{\circ} \mathrm{C}$ overnight. After washing with PBS, they were incubated with secondary antibody for $2 \mathrm{~h}$ at room temperature. The stained cells were observed under a laser scanning confocal microscope (Leica TCS SPE, Germany). Image analysis was performed using Image J software.

\section{Stereological cell counting of BrdU+ cells}

We used the stereological techniques to count the number of BrdU+ cell as described previously [49] . $\mathrm{BrdU}+$ and BrdU+/DCX+ cells from every eighth section covering the entire rostrocaudal axis of the DG were counted using a high-power (40x) microscope. Cells were counted in a blind manner. At least eight sections from both sides of the DG were counted per animal. The number for each group of animals is indicated in figure legends.

\section{ELISA}

Mice were anaesthetized by i.p. injection of $1 \%$ chloral hydrate, sacrificed and the brain was quickly removed. The separated tissues were lysed in ice-cold RIPA lysis buffer (R0020, Solarbio), then centrifuged at $14,000 \times \mathrm{g}$ at $4^{\circ} \mathrm{C}$ for $20 \mathrm{~min}$, and the supernatants were measured for soluble IL-1 $\beta$, IL-6, TNF-a, IL-4 and BDNF ELISAs (R\&D) according to the manufacturer's instructions. The values were expressed as amount per total protein.

\section{RT-PCR}

Total RNA from mice hippocampus and cortex was extracted using Trizol reagent (Invitrogen, USA). Reverse transcription was performed with an Exscript RT Reagent Kit (Takara Bio Inc., China). Real-time PCR analysis was undertaken using SYBR Premix Ex Taq (Takara Bio Inc., China). The primer sequences for IL-1 $\beta$ were 5'-CAAGGCCACAGGTATTTTGT-3' (sense) and 5'-GAAATGCCACCTTTTGACAG-3' (antisense). The primer sequences for IL-6 were 5'- GGCCTTCCCTACTTCACAAG -3' (sense) and 5'ATTTCCACGATTTCCCAGAG -3' (antisense). The primer sequences for TNF-a were 5'-

CAGCCTCTTCTCATTCCTGCTTGTG-3' (sense) and 5'- CTGGAAGACTCCTCCCAGGTATAT -3' (antisense). 
The primer sequences for IL-4 were 5'-GGCATTTTGAACGAGGTCAC-3' (sense) and 5'AAATATGCGAAGCACCTTGG-3' (antisense). The primer sequences for IL-10 were 5'-

ATTTGAATTCCCTGGGTGAGAAG-3' (sense) and 5'-CACAGGGGAGAAATCGATGACA-3' (antisense). The primer sequences for BDNF I were 5'-GCTTTGCGGATATTGCGAAGGGTT-3' (sense) and 5'-ACCTGGTGG AACATTGTGGCTTTG-3' (antisense). The primer sequences for BDNF II were 5'-

TGAAGTTGGCTTCCTAGCGGTGTA-3' (sense) and 5'-TGGTGGAACTTCTTT GCGGCTTAC-3' (antisense). The primer sequences for BDNF III were 5'-CCAGAGCAGCTGCCTTGATGTTTA -3' (sense) and 5'CCGCCTTCATGCAAC CGAAGTAT-3' (antisense). The primer sequences for BDNF IV were 5'-TGACAA CAATGTGACTCCACTGCC-3' (sense) and 5'-ATGGTCATCACTCTTCTCACCTGG-3' (antisense). Polymerase chain reaction parameters were $95^{\circ} \mathrm{C}$ for $3 \mathrm{~min}$, and 40 cycles of $95^{\circ} \mathrm{C}$ for $15 \mathrm{~s}$ and $60^{\circ} \mathrm{C}$ for $1 \mathrm{~min}$. The relative expression of the genes was normalized to the mean levels of $\beta$-actin.

\section{Western blot}

Western blot was performed as previously described [50] . Briefly, mice were anaesthetized by i.p. injection of chloral hydrate $(400 \mathrm{mg} / \mathrm{kg}$ ), sacrificed and the brain was quickly removed. The separated tissues were lysed in ice-cold RIPA lysis buffer (R0020, Solarbio), then centrifuged at $14,000 \times \mathrm{g}$ at $4^{\circ} \mathrm{C}$ for $20 \mathrm{~min}$, and the protein concentration in the extracts was determined by the Bradford assay (Thermo, Hercules, CA). The precipitates were denatured with SDS sample loading buffer and separated on $10 \%$ SDS-PAGE. Proteins were transferred onto nitrocellulose membranes using a Bio-Rad mini-protein-III wet transfer unit overnight at $4^{\circ} \mathrm{C}$. Transfer membranes were then incubated with blocking solution ( $5 \%$ nonfat dried milk dissolved in tris buffered saline tween (TBST) buffer (in $\mathrm{mM}$ ): $10 \mathrm{Tris}-\mathrm{HCl}, 150 \mathrm{NaCl}$, and $0.1 \%$ Tween-20) for $2 \mathrm{~h}$ at room temperature, and incubated with primary antibody overnight at $4^{\circ} \mathrm{C}$. The primary antibodies used in this experiment were phospho-PKA (Cell Signaling Technology, 1:1,000), PKA (Cell Signaling Technology, 1:1,000), phospho-CREB (Cell Signaling Technology, 1:1,000), CREB (Cell Signaling Technology, 1:1,000), phospho-P65 NF-kB (abcam, 1:1000), P65 NF-kB (abcam, 1:1000), CBP (abcam, 1:1000) and GAPDH (Boster, 1:3,000). Membranes were washed three times in TBST buffer and incubated with the appropriate secondary antibodies (LI-COR, Odyssey, 1:5,000) for $2 \mathrm{~h}$. Images were acquired with the Odyssey infrared imaging system and analyzed as specified in the Odyssey software manual. The results were expressed as the target protein/GAPDH ratio and then normalized to the values measured in the control groups (presented as $100 \%$ ).

\section{Novel object recognition (NOR)}

The NOR test was performed 14 days after stereotaxic surgery as previously described $[46,51]$. Briefly, mice received $2 \mathrm{~d}$ of habituation in a $45 \times 45 \mathrm{~cm}$ square arena, and on the third day, they were allowed to explore two identical objects made from large Lego bricks for $10 \mathrm{~min}$ (training trial). They were returned to their home cage, and $24 \mathrm{~h}$ later, a different shape and color object replaced one of the objects and the mice were returned to the arena for $10 \mathrm{~min}$ (testing trial). The time spent on each object was then calculated as a percentage of total object exploration.

\section{Y maze (YM)}


The $Y$ maze test was performed 18 days after stereotaxic surgery as previously described $[46,51]$. Briefly, the apparatus for YM was made of gray plastic, with each arm $40 \mathrm{~cm}$ long, $12 \mathrm{~cm}$ high, $3 \mathrm{~cm}$ wide at the bottom and $10 \mathrm{~cm}$ wide at the top. The three arms were connected at an angle of $120^{\circ}$. Mice were individually placed at the end of an arm and allowed to explore the maze freely for $8 \mathrm{~min}$. The total arm entries and spontaneous alternation percentage (SA\%) were measured. SA\% was defined as a ratio of the arm choices that differed from the previous two choices ('successful choices') to total choices during the run ('total entry minus two' because the first two entries could not be evaluated). For example, if a mouse made 10 entries, such as 1-2-3-2-3-1-2-3-2-1, there are 5 successful choices in 8 total choices (10 entries minus 2). Therefore, $\mathrm{SA} \%$ in this case is $62.5 \%$.

\section{Morris water maze (MWM)}

The MWM maze test was performed 19 days after stereotaxic surgery as previously described $[46,52]$. Briefly, the water maze of $1.50 \mathrm{~m}$ in diameter and $0.50 \mathrm{~m}$ in height was filled with water $\left(20 \pm 1^{\circ} \mathrm{C}\right)$ to maintain the water surface $1.50 \mathrm{~cm}$ higher than the platform $(10 \mathrm{~cm}$ in diameter). Water was dyed white and the tank was divided into four quadrants by four points: North (N), South (S), East (E), and West (W). The platform was placed at the center of either quadrant and video tracking software was used to automatically track the animals. Learning and memory acquisition lasts for five days. Animals were put into the water from four points in random order every day until they found the platform and stayed for 10 $\mathrm{s}$ within $1 \mathrm{~min}$. If the mice cannot find the platform within $1 \mathrm{~min}$, they were guided to the platform. Following acquisition test, on the sixth day, learning and memory maintenance test was carried on. The platform was removed, and the mice were placed in water from the opposite quadrant of the platform, and then the times crossing the platform was recorded within $1 \mathrm{~min}$.

\section{Statistical analysis}

Results are expressed as mean \pm SEM. Statistical analysis was performed by one-way ANOVAs followed by Tukey's post hoc comparisons or two-way ANOVAs followed by Bonferroni post hoc comparisons, using prism software. $P$ value $<0.05$ was considered statistically significant.

\section{Results}

\section{Thioperamide decreases LPS-induced microglial activation and pro-inflammatory cytokines production}

The study of the microglia response in the inflammatory process has been copiously supported by the use of LPS, a gram-negative cell wall component [53]. LPS binds to the CD14/TLR4/MD2 receptor complex, located on the cell membrane, triggering classical microglial responses such as proliferation, migration, phagocytosis and release of inflammatory mediators [54,55]. Therefore, LPS was used to evaluate the effect of thioperamide, a H3R antagonist on neuroinflammation in mice. We examined the activated microglia in DG of the hippocampus by Iba1 immunostaining. Results showed that the area of 
Iba $1^{+}$-cells in the hippocampal DG of LPS treated mice increased dramatically compared with the vehicle treated mice (from $0.9187 \pm 0.08736$ to $5.200 \pm 0.4575, P<0.001$, Figure $1 \mathrm{~A}, \mathrm{~B}$ ), which was reversed by administration of thioperamide (to $2.258 \pm 0.2632, P<0.01$, Figure $1 \mathrm{~A}, \mathrm{~B}$ ).

The activation of microglia may promote the pathological process of chronic neuroinflammation-related diseases through releasing of pro-inflammatory cytokines which could lead to neuronal damage and cognitive impairments $[56,57]$. Moreover, the inflammatory cytokines in neurodegenerative diseases are thought to lead to an impairment of neurogenesis [6]. Therefore, we investigated transcriptional and expressional level of pro-inflammatory factors in LPS treated mice. To confirm the effect of thioperamide on the gene transcription of inflammatory cytokines, we tested the effects of thioperamide on mRNA expression of IL-1 $\beta$, IL- 6 and TNF- $a$ by RT-PCR. We found that LPS up-regulated the mRNA level of proinflammatory cytokines IL-1 $\beta$ (increased to $363.8 \pm 39.05 \%$ of control, $p<0.01$, Figure 1C), IL-6 (increased to $431.7 \pm 84.46 \%$ of control, $p<0.01$, Figure 1D) and TNF-a (increased to $571.1 \pm 83.20 \%$ of control, $p<$ 0.001 , Figure 1E) in hippocampus. Interestingly, thioperamide decreased the mRNA level of IL-1 $\beta$ (decreased to $122.0 \pm 37.85 \%$ of control, $p<0.05$, Figure 1C), IL-6 (decreased to $150.0 \pm 15.90 \%$ of control, $p<0.01$, Figure 1D) and TNF-a (decreased to $187.8 \pm 63.97 \%$ of control, $p<0.001$, Figure $1 \mathrm{E}$ ). We further confirmed the effect of thioperamide on protein levels of inflammatory cytokines by ELISA. Similarly, we found that the upregulated protein level of IL-1 $\beta$ (from $311.0 \pm 44.29 \%$ to $109.5 \pm 23.29 \%$ of control, $p<0.01$, Figure 1F), IL-6 (from $280.8 \pm 42.87 \%$ to $110.3 \pm 26.32 \%$ of control, $p<0.05$, Figure $1 G$ ) and TNF- $a$ (from $262.8 \pm 18.67 \%$ to $116.3 \pm 22.52 \%$ of control, $p<0.001$, Figure $1 \mathrm{H}$ ) induced by LPS in hippocampus was significantly reversed by thioperamide. Taken together, all these results suggested that thioperamide could effectively suppress both activation of microglia and secretion of pro-inflammatory cytokines in LPS treated mice.

\section{Thioperamide ameliorates LPS-induced impairment of neurogenesis}

Normal aging might prime microglia towards the classic M1 phenotype, and increase basal release of the pro-inflammatory cytokines IL-1 $\beta$, interleukin- 6 and TNFa, which have been shown to reduce hippocampal neurogenesis [58]. Therefore, we next assessed the effect of thioperamide on adult neurogenesis in the DG region of the hippocampus. We examined the newborn cells labeled by BrdU in DG 1 day after the last time of LPS administration. The results indicated that the $\mathrm{BrdU}^{+}$cells in the DG region of hippocampus decreased in the vehicle group compared to the control group (decreased to $51.62 \pm 1.475 \%$ of control, $P$ $<0.001$, Figure $2 A, D$ ), and thioperamide rescued the decreased BrdU+ cells to $85.84 \pm 4.788 \%$ significantly $(P<0.001$, Figure $2 A, D)$.

To further investigate the effect of thioperamide on neurogenesis in LPS-treated mice, we analyzed the presence of neurogenesis in DG of hippocampus. Firstly, Doublecortin (DCX) ${ }^{+}$neuroblasts and immature neurons were detected. The results indicated that the number of $\mathrm{DCX}^{+}$cells decreased significantly after LPS treatment (decreased to $63.36 \pm 3.342 \%$ of control, $P<0.001$, Figure $2 \mathrm{~B}, \mathrm{E}$ ), which was reversed dramatically by administration of thioperamide (increased to $92.47 \pm 5.029 \%$ of control, $P<0.01$, Figure $2 \mathrm{~B}, \mathrm{E})$. The number of $\mathrm{BrdU}^{+} / \mathrm{DCX}^{+}$cells was also analyzed to assess the effect of thioperamide on 
immature newborn neurons. Results showed that the number of $\mathrm{BrdU}^{+} / \mathrm{DCX}^{+}$cells decreased significantly after LPS treatment (decreased to $37.25 \pm 1.307 \%$ of control, $P<0.001$, Figure $2 \mathrm{~B}, \mathrm{~F}$ ), and thioperamide remarkedly rescued the impairment of immature newborn neurons (increased to $85.62 \pm 4.999 \%$ of control, $P<0.001$, Figure 2B, F). Moreover, the percentage of $\mathrm{BrdU}^{+} / \mathrm{DCX}^{+}$newborn neuronal cells over $\mathrm{BrdU}^{+}$newborn cells was further analyzed, and the results showed that the decreased percentage of $\mathrm{BrdU}^{+} / \mathrm{DCX}^{+}$cells over $\mathrm{BrdU}^{+}$cells in the LPS treated mice was significantly reversed by administration of thioperamide (from $32.66 \pm 1.37 \%$ to $45.09 \pm 1.543 \%, P<0.05$, Figure $2 \mathrm{~B}, \mathrm{G}$ ).

We further examined the effect of thioperamide on mature newborn neurons in DG of hippocampus by $\mathrm{BrdU}^{+} / \mathrm{NeuN}^{+}$staining. Results showed that, number of $\mathrm{BrdU}^{+} / \mathrm{NeuN}^{+}$cells decreased significantly in the LPS vehicle group compared to the control group (decreased to $42.36 \pm 2.778 \%$ of control, $P<0.001$, Figure $2 \mathrm{C}, \mathrm{H}$ ), and thioperamide rescued the impairment of mature newborn neurons significantly (increased to $93.06 \pm 5.534 \%$ of control, $P<0.001$, Figure $2 \mathrm{C}, \mathrm{H}$ ). In addition, the percentage of $\mathrm{BrdU}^{+} / \mathrm{NeuN}^{+}$newborn mature neurons over $\mathrm{BrdU}^{+}$newborn cells were also analyzed, and the results showed that the decreased percentage of $\mathrm{BrdU}^{+} / \mathrm{NeuN}^{+}$cells over $\mathrm{BrdU}^{+}$cells in the LPS treated mice was significantly reversed by administration of thioperamide (from $31.44 \pm 0.8138 \%$ to $43.39 \pm 1.269 \%$, $P<0.01$, Figure $2 B, G)$.

Taken together, results above showed that thioperamide promoted neurogenesis in LPS induced neuroinflammation.

\section{Thioperamide alleviates LPS-induced cognitive dysfunction}

Neuroinflammation plays an important role in the onset and progression of neurodegenerative diseases such as aging and AD. LPS level is higher in the brains of AD patients and is associated with neuroinflammation and cognitive dysfunction [59]. in this research, we studied the effect of thioperamide on LPS-induced cognitive decline. The NOR test indicated that time spending on novel objection decreased significantly in the LPS group compared with the control group (from $70.15 \pm 2.384 \%$ to 51.57 $\pm 4.737 \%, P<0.01$,Figure $3 \mathrm{~A}$ ). Administration of thioperamide significantly increased the time spending on novel object (to $66.07 \pm 2.282 \%, P<0.05$,Figure $3 \mathrm{~A}$ ) in LPS treated mice. In the YM test, we observed a decreased spontaneous alternation \% (SA\%) in the LPS group compared with the control group (from $83.20 \pm 3.751 \%$ to $57.08 \pm 7.202 \%, P<0.01$, Figure 3B). Administration of thioperamide increased the SA\% to $81.40 \pm 4.007 \%$ significantly in LPS treated mice $(P<0.05$, Figure $3 A)$. In morris water maze (MWM) test, the escape latency increased significantly in the LPS group on day 3 to day $5(P<0.05$, Figure $3 C$ ). Administration of thioperamide significantly decreased the escape latency $(P<0.01$, Figure 3C) in LPS treated mice. Moreover, times crossing the platform decreased in LPS treated mice (from $7.000 \pm 0.5669$ to $3.500 \pm 0.4226, P<0.01$, Figure 3D) on day 6 , and administration of thioperamide increased it significantly (to $6.250 \pm 0.5901, P<0.05$, Figure 3D) in LPS treated mice. Results above suggested that thioperamide improved the cognitive impairments in in LPS treated mice. 


\section{The effects of thioperamide on neuroinflammation, neurogenesis and cognition involve histamine dependent $\mathrm{H} 2 \mathrm{R}$ activation}

Histamine has been shown to counteract LPS-induced glial activation and release of pro-inflammatory cytokines release as well as neurogenesis impairment [40,53]. Moreover, numerous evidences indicated that central histamine have an important role in cognitive function as it has been shown to enhance memory [60]. As a presynaptic receptor on histaminergic neurons, H3R suppresses histamine synthesis and releases in a negative feedback way. Therefore, inhibition of H3R by thioperamide leads to enhanced synaptic histamine release [47]. In order to confirm whether or not the effects of thioperamide are histamine dependent, pyrilamine or cimetidine, antagonist of H1R or H2R, was applied.

We found that the effect of thioperamide on the area of ionized calcium binding adapter molecule 1 (Iba1) ${ }^{+}$-cells in hippocampal DG region was reversed by administration of $\mathrm{H} 2 \mathrm{R}$ antagonist cimetidine (from $2.258 \pm 0.2632$ to $4.914 \pm 0.7837$ of control, $P<0.01$, Figure $1 \mathrm{~A}, \mathrm{~B}$ ) but not H1R antagonist pyrilamine (from $2.258 \pm 0.2632$ to $2.288 \pm 0.3927$ of control, $P>0.05$, Figure1A, B). Moreover, the inhibited transcription of pro-inflammatory cytokines was reversed by cimetidine (IL-1 $\beta$ levels from 109.5 \pm 23.29 of control to $298.4 \pm 37.33$ of control, $P<0.05$, Figure 1 C; IL-6 levels from $110.3 \pm 26.32$ of control to $260.0 \pm 40.27$ of control, $P<0.01$, Figure 1D; TNFa levels from $116.3 \pm 22.52$ to $240.0 \pm 24.06$ of control, $P<0.01$, Figure 1E) but not pyrilamine (IL-1 $\beta, P>0.05$, Figure 1C; IL-6, $P>0.05$, Figure 1D; TNFa $P$ $>0.05$, Figure $1 \mathrm{E}$ ). Similarly, decreased protein levels of pro-inflammatory cytokines were also reversed by cimetidine (IL-1 $\beta$ levels from $122.0 \pm 37.85$ to $329.0 \pm 79.83$ of control, $P<0.01$, Figure 1F; IL-6 levels from $150.0 \pm 15.90$ to $437.0 \pm 63.22$ of control, $P<0.05$, Figure $1 \mathrm{G}$; TNFa levels from $187.8 \pm 63.97$ to $521.7 \pm$ 45.74 of control, $P<0.01$, Figure $1 \mathrm{H}$ ) but not pyrilamine (IL-1 $\beta, P>0.05$, Figure 1F; IL-6, $P>0.05$, Figure 1G; TNFa $P>0.05$, Figure $1 \mathrm{H}$ ). Above all, these results showed that thioperamide inhibited LPS induced microglial activation and inflammatory response through histamine dependent $\mathrm{H} 2 \mathrm{R}$ activation.

We further examined the role of histamine in the enhanced neurogenesis offered by thioperamide in LPS treated mice. As expect, we found that the $\mathrm{BrdU}^{+}$cells in the $\mathrm{DG}$ region of hippocampus were reversed by administration of cimetidine (from $85.84 \pm 4.788$ to $50.15 \pm 3.789$ of control, $P<0.001$, Figure $2 A, D$ ) but not pyrilamine (from $85.84 \pm 4.788$ to $88.20 \pm 2.814$ of control, $P>0.05$, Figure2A, D). Otherwise, the number of $\mathrm{BrdU}^{+} / \mathrm{DCX}^{+}$cells and $\mathrm{BrdU}^{+} / \mathrm{NeuN}^{+}$cells were both compromised by administration of cimetidine (BrdU $/ \mathrm{DCX}^{+}$cells from $85.62 \pm 4.999$ to $34.64 \pm 2.216$ of control, $P<0.001$, Figure $2 \mathrm{~B}, \mathrm{~F}$; $\mathrm{BrdU}^{+} / \mathrm{NeuN}^{+}$cells from $93.06 \pm 5.534$ to $43.06 \pm 1.770$ of control, $P<0.001$, Figure $2 \mathrm{C}, \mathrm{H}$ ) but not pyrilamine $\left(\mathrm{BrdU}^{+} / \mathrm{DCX}{ }^{+}\right.$cells, $P>0.05$, Figure2A, $\mathrm{D}$; $\mathrm{BrdU}^{+} / \mathrm{NeuN}^{+}$cells from $2.258 \pm 0.2632$ to $2.288 \pm$ 0.3927 of control, $P>0.05$, Figure2A, D). Taken together, these results suggested that thioperamide rescued LPS induced impaired neurogenesis through histamine dependent H2R activation.

Finally, we tested whether histamine was involved in the alleviated cognitive impairment offered by thioperamide in LPS treated mice. The NOR test showed that time spending on novel objection was reversed by administration of cimetidine (from $66.07 \pm 2.282 \%$ to $52.62 \pm 3.254 \%$ of control, $P$ $<0.05$,Figure $3 \mathrm{~A}$ ) but not pyrilamine (from $66.07 \pm 2.282 \%$ to $65.33 \pm 2.483 \%$ of control, $P>0.05$,Figure 
$3 \mathrm{~A}$ ). The YM test also showed that SA\% was reversed by administration of cimetidine (from $81.40 \pm$ $4.007 \%$ to $58.59 \pm 5.367 \%$ of control, $P<0.05$,Figure $3 \mathrm{~B}$ ) but not pyrilamine (from $81.40 \pm 4.007 \%$ to 81.27 $\pm 3.499 \%$ of control, $P>0.05$,Figure $3 \mathrm{~B})$. In the MWM test, the escape latency was reversed by administration of cimetidine ( $P<0.05$,Figure 3C) but not pyrilamine ( $P>0.05$,Figure $3 C)$ on day 4 to day 5 . In addition, increased times crossing the platform offered by thioperamide was reversed by cimetidine (from $6.250 \pm 4.007 \%$ to $3.375 \pm 0.8004 \%$ of control, $P<0.05$,Figure 3D) but not pyrilamine ( $P>0.05$, Figure 3D). In all, results above showed that thioperamide alleviated LPS induced cognitive dysfunction through histamine dependent $\mathrm{H} 2 \mathrm{R}$ activation.

\section{Thioperamide reverses LPS-induced inactivation of PKA/CREB pathway via histamine dependent H2R activation}

Results above showed that histamine dependent H2R activation is involved in the protection against LPS induced inflammatory response. Recent reports indicate that $\mathrm{H} 2 \mathrm{R}$ and its downstream activation of CAMP/PKA is also necessary to the inhibited immune response of histamine [61,62]. Moreover, CAMP/PKA/CREB signaling is considered to play an important role in the suppression of microglia activation and its related neuroinflammation by inhibiting NF-KB activation $[63,64]$. Thus, in order to elucidate the mechanisms of the anti-inflammatory offered by thioperamide in LPS treated mice, we investigated the H2R downstream protein level of PKA and CREB. In consistent with the previous reports, decreased p-PKA and p-CREB level were observed in hippocampus in LPS treated mice (p-PKA decreased to $55.89 \pm 7.068 \%$ of control group, $P<0.01$, Figure $4 \mathrm{~A}$, B; $\mathrm{p}$-CREB decreased to $55.87 \pm 3.954 \%$ of control group, $P<0.001$, Figure $4 A, C$ ). As expect, thioperamide up-regulated the $p$-CREB expression (p-PKA increased to $97.94 \pm 18.63 \%$ of control group, $P<0.05$, Figure 4A, B; $p$-CREB increased to $90.00 \pm 6.892 \%$ of control group, $P<0.01$, Figure $4 \mathrm{~A}, \mathrm{C}$ ), which was reversed by cimetidine (p-PKA decreased to $59.38 \pm$ $8.18 \%$ of control group, $P<0.05$, Figure 4A, B; p-CREB decreased to $59.32 \pm 3.999 \%$ of control group, $P<$ 0.01 , Figure $4 A, C$ ) but not pyrilamine, suggesting thioperamide activated the $H 2 R$ downstream PKA/CREB signaling.

The phosphorylated CREB exerts a dual function in inflammatory response. First, by forming a complex with CBP to activate transcription of anti-inflammatory cytokines such as IL-4, IL-10 as well as BDNF. Secondly, activated CREB blocks the nuclear factor kappa-B (NF-KB)/CBP interaction, which is responsible for the transcription of pro-inflammatory cytokines such as IL-1 $\beta$, IL-6 and TNFa $[65,66]$. Therefore, we examined whether the activated CREB offered by thioperamide might regulate the activity of NF-KB. As expect, increased p-NF-KB level was observed in hippocampus in LPS treated mice (increased to $197.5 \pm 17.96 \%$ of control group, $P<0.001$, Figure $4 A, D$ ). interestingly, thioperamide decreased the p-NF-kB expression significantly (decreased to $92.72 \pm 11.99 \%$ of control group, $P<0.001$, Figure 4A, D), which was reversed by cimetidine (increased to $177.0 \pm 15.81 \%$ of control group, $P<0.01$, Figure 4A, D) but not pyrilamine, suggesting that thioperamide inhibited the activation of NF-KB signaling in LPS treated mice via activating $\mathrm{H} 2 \mathrm{R}$. 
Furthermore, we also examined the effects of thioperamide on the interaction of both CREB/CBP and NF$\mathrm{KB} / \mathrm{CBP}$. Interestingly, we found that the LPS induces decreased CREB/CBP (decreased to $56.64 \pm 3.195 \%$ of control group, $P<0.05$, Figure $4 \mathrm{E}, \mathrm{F}$ ) but increased NF-KB/CBP (increased to $599.0 \pm 47.92 \%$ of control group, $P<0.001$, Figure4E, G) interaction. However, thioperamide significantly increased the interaction of CREB/CBP (increased to $113.2 \pm 5.767 \%$ of control group, $P<0.01$, Figure $4 \mathrm{E}, \mathrm{F}$ ) but decreased NF$\mathrm{KB} / \mathrm{CBP}$ (decreased to $111.8 \pm 23.41 \%$ of control group, $P<0.001$, Figure $4 \mathrm{E}, \mathrm{G}$ ). The effects of thioperamide on the regulation of CREB/NF-KB/CBP interaction was reversed by cimetidine (CREB/CBP: decreased to $55.57 \pm 8.421 \%$ of control group, $P<0.01$, Figure $4 \mathrm{E}$, F; NF-KB/CBP: increased to $504.6 \pm$ $53.00 \%$ of control group, $P<0.001$, Figure $4 \mathrm{E}, \mathrm{G}$ ) but not pyrilamine, indicating an $\mathrm{H} 2 \mathrm{R}$ dependent effects offered by thioperamide.

\section{Thioperamide promotes polarization of M2 microglia from M1 microglia via activating PKAVCREB pathway in LPS-treated mice}

In order to further investigate the involvement of PKA/CREB signaling in the effects of thioperamide on the activation of microglia, H89, the inhibitor of PKA/CREB was administrated to inhibit p-CREB. The results showed that the area of Iba $1^{+}$-cells in hippocampus DG markedly increased in the thioperamide + H89 group compared with the thioperamide group in LPS treated mice (from $2.542 \pm 0.3964$ to $5.114 \pm$ $0.4003, P<0.001$, Figure 5A, B).

Reports have shown that CREB is involved in polarizing microglia from M1 to M2 phenotype. M1 microglia produce pro-inflammatory cytokines, such as IL-1 $\beta$, IL- 6 and TNF- $a$, whereas M2 microglia produce anti-inflammatory cytokines such as IL-4, IL-10 and BDNF [13]. Thus, we further investigated the involvement of PKA/CREB signaling in the effect of thioperamide on microglia phenotypes. Firstly, we examined the role of CREB activation in the secretion of M1 microglia related pro-inflammatory cytokines, including IL-1 $\beta$, IL- 6 and TNF-a. Results showed that the decreased mRNA level of all the three proinflammatory cytokines offered by thioperamide in hippocampus were reversed significantly after $\mathrm{H} 89$ treatment (IL-1 $\beta$ : from $40.28 \pm 11.50$ to $86.62 \pm 1.721$ of vehicle, $P<0.01$; IL-6: from $37.12 \pm 4.813$ to $88.47 \pm 4.688$ of vehicle, $P<0.01$; TNFa: from $43.27 \pm 13.97$ to $91.37 \pm 7.308$ of vehicle, $P<0.05$; Figure $5 C$ ) in LPS treated mice. Otherwise, a reversed protein level of three pro-inflammatory cytokines were also observed in the Thio+H89 group compared with the thio group in hippocampus (IL-1 $\beta$ : from $40.76 \pm 8.946$ to $95.35 \pm 5.991$ of vehicle, $P<0.01$; IL-6: from $38.55 \pm 9.505$ to $88.15 \pm 4.179$ of vehicle, $P<0.05$; TNFa: from $48.36 \pm 9.778$ to $98.20 \pm 4.629$ of vehicle, $P<0.01$; Figure $5 \mathrm{D}$ ) in LPS treated mice.

Secondary, we investigated the role of CREB activation in the secretion of M2 microglia related antiinflammatory cytokines and neurotrophic factors, including IL-4, IL-10 and BDNF. Interestingly, we found that administration of thioperamide up-regulated the transcription of anti-inflammatory cytokines IL-4 (increased to $254.1 \pm 54.91$ of vehicle, $P<0.001$, Figure 5E), IL-10 (increased to $258.9 \pm 47.13$ of vehicle, $P$ $<0.05$, Figure 5E) and neurotrophic factors BDNF (BDNF I: increased to $286.8 \pm 66.33$ of vehicle, $P<0.05$; BDNF II: increased to $342.2 \pm 40.23$ of vehicle, $P<0.01$; BDNF III: increased to $281.1 \pm 42.78$ of vehicle, $P$ $<0.01$; BDNF IV: increased to $246.2 \pm 36.64$ of vehicle, $P<0.01$, Figure $5 \mathrm{G}$ ), which were all reversed by $\mathrm{H} 89$ 
to suppress CREB activation (IL-4: to $110.4 \pm 9.017$ of vehicle, $P<0.001$; IL-10: to $110.9 \pm 26.56$ of vehicle, $P<0.05$, Figure 5E; BDNF I: to $111.0 \pm 10.91$ of vehicle, $P<0.05$; BDNF II: to $152.0 \pm 43.82$ of vehicle, $P$ <0.01; BDNF III: to $133.6 \pm 17.09$ of vehicle, $P<0.05$; BDNF IV: to $109.9 \pm 23.48$ of vehicle, $P<0.05$, Figure $5 G)$ in LPS treated mice. In addition, results also showed that administration of H89 compromised the upregulated expression of IL-4 (from $270.2 \pm 15.93$ to $128.7 \pm 19.82$ of vehicle, $P<0.001$, Figure $5 \mathrm{~F}$ ), IL-10 (from $203.7 \pm 9.452$ to $118.8 \pm 15.97$ of vehicle, $P<0.01$, Figure $5 \mathrm{~F}$ ) and BDNF (from $199.9 \pm 16.67$ to $109.2 \pm 12.62$ of vehicle, $P<0.01$, Figure $5 \mathrm{H}$ ) offered by thioperamide in LPS treated mice.

Taken together, these results indicated that thioperamide promoted switch of microglia from M1 to M2 phenotype through activating H2R downstream PKA/CREB signaling.

\section{Thioperamide enhances neurogenesis via activating PKAVCREB pathway in LPS-treated mice}

Studies have shown that activation of CREB promoted neurogenesis [46, 67-70], and enhanced neurite outgrowth and dendritic branching [71]. Therefore, we investigated whether the PKA/CREB signaling was involved in thioperamide induced neurogenesis in LPS treated mice by using $\mathrm{H} 89$. We found that the increased $\mathrm{BrdU}^{+}$cells in the DG region of hippocampus were reversed by administration of $\mathrm{H} 89$ (from $247.7 \pm 14.02$ to $134.6 \pm 9.957$ of vehicle, $P<0.001$, Figure $6 \mathrm{~A}, \mathrm{D})$. The increased number of $\mathrm{DCX}^{+}$cells was reversed dramatically by $\mathrm{H} 89$ (from $147.1 \pm 7.805 \%$ to $107.3 \pm 8.417 \%$ of vehicle, $P<0.05$, Figure $6 \mathrm{~B}$, E). Moreover, the number of $\mathrm{BrdU}^{+} / \mathrm{DCX}^{+}$cells and $\mathrm{BrdU}^{+} / \mathrm{NeuN}^{+}$cells were also both compromised by $\mathrm{H} 89\left(\mathrm{BrdU}^{+} / \mathrm{DCX}^{+}\right.$cells from $270.4 \pm 21.79$ to $113.0 \pm 10.72$ of vehicle, $P<0.001$, Figure $6 \mathrm{~B}, \mathrm{~F}$; $\mathrm{BrdU}^{+} / \mathrm{NeuN}^{+}$cells from $221.3 \pm 6.858$ to $104.9 \pm 5.437$ of vehicle, $P<0.001$, Figure $6 \mathrm{C}, \mathrm{H}$ ). Moreover, administration of $\mathrm{H} 89$ reversed thioperamide mediated increased percentage of both $\mathrm{BrdU}^{+} / \mathrm{DCX}^{+}(\mathrm{from}$ $50.20 \pm 1.925$ to $35.41 \pm 3.633, P<0.05$, Figure $6 \mathrm{~B}, \mathrm{~F}$ ) and $\mathrm{BrdU}^{+} / \mathrm{NeuN}^{+}$(from $46.89 \pm 2.322$ to $35.11 \pm$ 2.352, $P<0.01$, Figure 6C, F) newborn neuronal cells in LPS treated mice. Above all, these results suggested that thioperamide promoted hippocampal neurogenesis by activating H2R downstream PKA/CREB signaling.

\section{Thioperamide increases the dendritic complexity via activating PKAVCREB pathway in LPS-treated mice}

The previous studies have shown that the pro-inflammatory cytokines can induce abnormal neuronal morphology and promote the loss of synapses in AD [40,72-74]. Therefore, we explored the effects of thioperamide on morphologies of neurons and further analyzed the involvement of PKA/CREB signaling. We examined both $\mathrm{DCX}^{+}$immature neurons and MAP2 ${ }^{+}$mature neurons in LPS treated mice. We found that thioperamide significantly increased either total dendritic length (from $354.4 \pm 33.70$ to $500.5 \pm$ 34.16, $P<0.05$, Figure 7A, C) or total branches (from $4.6 \pm 0.7483$ to $8.400 \pm 0.5099, P<0.01$, Figure 7A, D) in LPS treated mice by DCX staining, which was reversed by H89 (total dendritic length: to $361.2 \pm 34.03$, $P<0.05$, Figure 7A, C; total branches: to $5.400 \pm 0.6782, P<0.05$, Figure 7A, D). Moreover, thioperamide also alleviated the abnormal morphologies of mature neurons (total dendritic length: from $729.9 \pm 38.29$ to $1025 \pm 78.92, P<0.01$, Figure 7B, E; total branches: from $9.600 \pm 0.5099$ to $12.60 \pm 0.600, P<0.05$, Figure 7B, F), and was compromised by H89 (total dendritic length: to $743.2 \pm 25.98, P<0.01$, Figure 7B, E; 
total branches: to $10.00 \pm 0.7071, P<0.05$, Figure $7 \mathrm{~B}, \mathrm{~F})$. Above all, these results showed that thioperamide rescued the abnormal morphologies of neurons through activating $\mathrm{H} 2 \mathrm{R}$ dependent PKA/CREB signaling.

\section{Discussion}

In the present study, we have shown that inhibition of H3R by thioperamide inhibited microglial activation, suppressed inflammatory response and further enhanced neurogenesis in LPS induced neuroinflammation in mice. Importantly, the alleviated effects of thioperamide on reactivity of microglia, neuroinflammation, neurogenesis and cognitive function were all compromised by cimetidine but not pyrilamine, suggesting a mechanism involvement of histamine dependent $\mathrm{H} 2 \mathrm{R}$ activation. Moreover, $\mathrm{H} 89$ reversed the decreased phosphorylation of NF-KB, and the increased interaction of CREB-CBP offered by thioperamide, suggesting an underlying mechanism involving H2R-CAMP/PKA/CREB signaling.

Up to now, the population of aged individuals is increasing worldwide with significant health and socioeconomic implications. Studies on aging have discovered myriad changes in the brain, including reduced neurogenesis, increased synaptic aberrations, higher metabolic stress associating with cognitive decline [11]. Accumulating evidence suggests that the pathological changes occurs in part because the environment is affected during disease in a cascade of processes collectively termed neuroinflammation [75]. Microglia are the resident immune cells in CNS and play a pivotal role in maintaining brain homeostasis. In the aging brain, microglia lose their homeostatic molecular signature and show profound functional impairments, such as increased production of pro-inflammatory cytokines and buildup of dysfunctional lysosomal deposits indicative of impaired phagocytosis [76]. In aging pathogenesis, microglia activation plays a dual role: on one side, activation of pro-inflammatory M1 microglia contributes to neurotoxicity and synapse loss by triggering several proinflammatory cascades. In contrary, acute activation of anti-inflammatory M2 microglia induces increased phagocytosis or clearance [77].

Up to now, no therapy is available to block or slow down aging related diseases such as AD, and the involved mechanisms are still not fully understood [78]. In the CNS, the histaminergic system is involved in regulating many basic physiological functions including cognition [79]. H3R is a presynaptic autoreceptor negatively regulating histamine release from histaminergic neurons [23, 24], which suggesting inhibition of H3R induces increased histamine release. Therefore, we studied the effect of H3R antagonist in neuroinflammation induced pathology in mice. We found that under LPS induced neuroinflammatory condition, inhibition of H3R by thioperamide significantly inhibited activation of microglia. Meanwhile, thioperamide also inhibited the pro-inflammatory cytokines transcription and expression. The mechanism might be related to its upregulated release of histamine and subsequent activation of $\mathrm{H} 2 \mathrm{R}$, because inhibiting histaminergic neurons by $\mathrm{H} 2 \mathrm{R}$ antagonist cimetidine but not $\mathrm{H} 1 \mathrm{R}$ antagonist pyrilamine reversed the microglia activation and anti-inflammatory effects of thioperamide. In accordance with these results, our previous study showed that thioperamide offered anti-inflammatory effects in AD [37]. Moreover, other study also shows that H3R antagonist JNJ10181457 reduces the 
upregulation of microglial pro-inflammatory cytokines and improved depression-like behavior, which is consistent with our results [80]. Conversely, there is also report shows activation but not inhibition of microglial H3R suppresses acute LPS-induced proinflammatory activities in primary cultured microglia [81]. Concerning that acute moderate activation of microglia promotes anti-inflammation M2 microglia phenotypes, whereas chronic microglial activation exerts pro-inflammation M1 phenotypes [82]. The differences might be attributed to the regulation of two different polarization of microglia by different factors.

Based on these studies, we found for the first time that the mechanism by which thioperamide offered anti-inflammatory effects was related to up-regulated histamine release and subsequent H2R activation. This is in accordance with other reports showing that histamine was able to counteract LPS-induced glial activation and release of pro-inflammatory molecules [40]. Depletion of histaminergic neurons in the hypothalamus induces potentiated microglial response to challenge with LPS in histidine decarboxylase (HDC) knockout mice [83]. In contrast, other reports show that histamine promotes microglia activation and induces phagocytosis $[84,85]$. These contradictory studies may be due to the different regulation of two microglia polarization under different circumstance through activating different receptors. Although histamine is acknowledged to be involved in promoting inflammatory effects in the peripheral system, accumulating evidences show that in the CNS, histamine has a dual role in the modulation of microglial inflammatory responses. ${ }^{85} \mathrm{Histamine} \mathrm{per} \mathrm{se} \mathrm{triggers} \mathrm{microglia} \mathrm{activation} \mathrm{and} \mathrm{inflammation,} \mathrm{whereas}$ exerts anti-inflammatory effects under stress induced pathological conditions $[40,53,86]$. Moreover, activation of H1R induces activation of microglia and pro-inflammatory effects [84, 85] but H2R induces inhibition of microglia and anti-inflammatory effects $[39,62,87]$.

Neuroinflammation is a significant pathological feature affecting cognition in aging, and recent evidence demonstrates that it also negatively affects hippocampal neurogenesis [6]. We observed that under LPS induced physiological conditions, thioperamide promoted hippocampal neurogenesis significantly through a histamine dependent mechanism. In concomitant with our results, either H3R antagonist or histamine has been shown to upregulate neurogenesis [40, 41, 43], showing that activating histaminergic neurons may represent a new tool for brain repair strategies in CNS. Interestingly, we found that the effects of thioperamide on neurogenesis involves activating histamine $\mathrm{H} 2 \mathrm{R}$, because they were reversed by cimetidine but not pyrilamine. In support with our results, other studies also show that histamine play a vital role in cerebral neurogenesis by activation of $\mathrm{H} 2 \mathrm{R}$ to promote proliferation of neural precursors [88]. However, some reports also show that $\mathrm{H} 1 \mathrm{R}$ is involved in the promoted neurogenesis offered by histamine in traumatic brain injury [43]. Moreover, deficiency of H1R leads to a reduced neurogenesis and cognition [89]. The different mechanism offered by histamine on neurogenesis might be related to different pathologies of diseases. It is possible that under chronic neuroinflammation, inflammatory blockade by histamine rescues impaired neurogenesis via activating H2R. Because a majority of studies indicate that anti-inflammatory drug restores neurogenesis [17, 90, 91]. Moreover, we also observed a relationship of histamine dependent $\mathrm{H} 2 \mathrm{R}$ activating and neuroinflammation induced cognition. Although reports show that both $\mathrm{H} 1 \mathrm{R}$ and $\mathrm{H} 2 \mathrm{R}$ mediates effects of histamine on cognition. In 
chronic neuroinflammation related diseases such as aging, AD, schizophrenia, and autism spectrum disorder, histamine promotes cognition mainly through modulating microglial function [92]. Meanwhile, histamine exerts its effects on microglia and neuroinflammation mostly through activating H2R [64, 89]. Therefore, the alleviated cognitive impairment by H2R activating might be related to its suppression on microglia activation and neuroinflammation.

To further understand the molecular mechanism underlying the effect mediated by $\mathrm{H} 2 \mathrm{R}$, we examined the $\mathrm{H} 2 \mathrm{R}$ downstream signaling PKA/CREB. Reduced $\mathrm{p}$-CREB level has been observed in neurodegenerative diseases $[93,94]$. In addition, the decreased p-CREB expression is also thought to be important for regulation of microglia activation and neuroinflammation in CNS [95-97]. Stimulating CREB pathway enhances M2 microglia polarization[98] and inhibits microglia-mediated neuroinflammation [63, 99]. Therefore, CREB might play an important role in mediating the effect of $\mathrm{H} 2 \mathrm{R}$ activation on neuroinflammation by histamine. Moreover, It is well acknowledged that activation of $\mathrm{H} 2 \mathrm{R}$ induces activating CAMP/PKA/CREB pathway [100]. Therefore, we investigated the effect of thioperamide on PKA/CREB phosphorylation in LPS induced neuroinflammation. In agreement with previous studies, we found that LPS induced neuroinflammation was accomplished by decreased levels of $p$-PKA and $p$-CREB, which were both reversed by thioperamide treatment, showing thioperamide activated the PKA/CREB pathway in LPS induced neuroinflammation. Specially, both cimetidine, an H2R antagonist and H89, an inhibitor of PKA/CREB compromised the effects offered by thioperamide, including decreased microglia activity, decreased inflammatory cytokines levels and neurogenesis, further suggesting that the antiinflammatory effects and promoted neurogenesis offered by thioperamide involves activation of H2RPKA/CREB pathway.

The expression of pro-inflammatory cytokines requires NF-KB activation and its nuclear translocation to interact with DNA [101]. Studies indicate that activation of CREB induces reduced expression of $\mathrm{p}-\mathrm{NF}-\mathrm{KB}$ and decreased production of pro-inflammatory cytokines in brain injury [102]. We found that LPS induced activation of NF-KB, and thioperamide mitigated this effect, showing thioperamide inhibited LPS induced activation of NF-KB. A critical step in the transcriptional regulation mediated by NF-KB or CREB is the interaction of each of these transcription factors with the co-activator CBP [103]. Interaction of NF-KB$\mathrm{CBP}$ mediates pro-inflammatory cytokines release whereas CREB-CBP mediates anti-inflammatory cytokines release [64]. Interestingly, we found that LPS induced an increased interaction of NF-KB-CBP but decreased CREB-CBP. Thioperamide promoted CREB-CBP but inhibited NF-KB-CBP interaction, which were both reversed by cimetidine, suggesting that thioperamide promoted CREB-CBP combination via histamine dependent activating H2R. Studies indicate that activation of CREB induces reduced expression of p-NF-KB and decreased production of pro-inflammatory cytokines in brain injury [102]. Consistent with these results, we found that thioperamide inhibited transcriptional and protein levels of pro-inflammatory cytokines, including IL-1, IL-6 and TNFa from M1 microglia but promoted antiinflammatory cytokines and neurotrophic factor including IL-4, IL-10 and BDNF from M2 microglia, which were both reversed by $\mathrm{H} 89$, suggesting that thioperamide regulated inflammatory cytokines transcription through activating CREB. Phosphorylation of CREB induced by thioperamide might promoted CREB-CBP 
interaction but inhibited NF-KB-CBP interaction to transcriptional regulate the inflammatory cytokines levels.

\section{Conclusions}

In conclusion, the present study indicates that H3R antagonist thioperamide improved cognitive impairment in LPS treated mice via histamine dependent H2R downstream up-regulating CREB-CBP interaction mediated inhibited M1 microglia related pro-inflammatory cytokines and M2 microglia related anti-inflammatory cytokines transcription, which contributed to neurogenesis (Figure 9). These results uncovered a novel mechanism behind the therapeutic effect of thioperamide in neuroinflammation and further provided an experimental basis for starting a clinical trial for H3R antagonists as a treatment for chronic neuroinflammation related diseases such aging and AD.

\section{Abbreviations}

$D G$, dentate gyrus; $A D$, alzheimer's disease; $H 3 R$, histamine $H 3$ receptor; $L P S$, lipopolysaccharide; $H 2 R$, histamine $\mathrm{H} 2$ receptor; PKA, protein kinase $\mathrm{A}$; CREB, cyclic AMP response element-binding protein; NF-KB, nuclear factor kappa-B; CBP, CREB binding protein; IL-4, interleukin-4; IL-10, interleukin-10; BDNF, brainderived neurotrophic factor; IL-1 $\beta$, interleukin-1 $\beta$; IL-6, interleukin-6; TNFa, tumor necrosis factor $\alpha$; GL, granule cell layer; CNS, central nervous system; IGF-1, insulin-like growth factor-1; AC, adenylyl cyclase; NSCs, neural stem cells; BrdU, 5-bromo-2'-deoxyuridine; NOR, novel object recognition; YM, Y maze; MWM, morris water maze; BSA, bovine serum albumin; DCX, Doublecortin; spontaneous alternation\% SA\%; Iba1, ionized calcium binding adapter molecule $1 ; \mathrm{HDC}$, histidine decarboxylase

\section{Declarations}

\section{Funding}

This study was supported by National Natural Science Foundation of China (81500930, 81901380, 82101584), Natural Science Foundation of Shandong Province (ZR202102190580, ZR2014HQ014, ZR2017BC047, ZR202103020494), College Student Innovation and Entrepreneurship Training Program (S202110440148) and Research Start-up Fund of Binzhou Medical College (BY2019KJ01, BY2020KJ12).

\section{Availability of data and materials}

The datasets used and/or analyzed during the current study are available from the corresponding author on reasonable request.

\section{Authors' contributions}

HY conceived and designed the project. HY, JW, BL, FS, YX, DZ, HL, MY, CW, JL, WW, DL and LS performed the experiments. HY and JW analyzed the data and drafted the manuscript. All authors reviewed the 
manuscript. All authors read and approved the final manuscript.

\section{Ethics approval and consent to participate}

Not applicable

\section{Consent for publication}

Not applicable

\section{Competing interests}

The authors declare no competing interests.

\section{Acknowledgements}

Not applicable

\section{Author details}

${ }^{1}$ Medical Research Center, Binzhou Medical University Hospital, Binzhou, China

${ }^{2}$ Department of Pharmacology, School of Basic Medicine, Binzhou Medical University, Yantai, China

${ }^{3}$ Department of Anatomy, School of Basic Medicine, Binzhou Medical University, Yantai, China.

${ }^{\dagger}$ These authors contributed equally to this work.

\section{References}

1. Ming GL, Song H. Adult neurogenesis in the mammalian brain: significant answers and significant questions. Neuron. 2011; 70:687-702.

2. Goncalves JT, Schafer ST, Gage FH. Adult Neurogenesis in the Hippocampus: From Stem Cells to Behavior. Cell. 2016; 167:897-914.

3. Lazarov O, Mattson MP, Peterson DA, Pimplikar SW, van Praag H. When neurogenesis encounters aging and disease. Trends Neurosci. 2010; 33:569-79.

4. Ruan L, Lau BW, Wang J, Huang L, Zhuge Q, Wang B, Jin K, So KF. Neurogenesis in neurological and psychiatric diseases and brain injury: from bench to bedside. Prog Neurobiol. 2014; 115:116-37.

5. Cameron HA, Glover LR. Adult neurogenesis: beyond learning and memory. Annu Rev Psychol. 2015; 66:53-81.

6. Ryan SM, Nolan YM. Neuroinflammation negatively affects adult hippocampal neurogenesis and cognition: can exercise compensate? Neurosci Biobehav Rev. 2016; 61:121-31. 
7. Green HF, Nolan YM. Inflammation and the developing brain: consequences for hippocampal neurogenesis and behavior. Neurosci Biobehav Rev. 2014; 40:20-34.

8. Taliaz D, Stall N, Dar DE, Zangen A. Knockdown of brain-derived neurotrophic factor in specific brain sites precipitates behaviors associated with depression and reduces neurogenesis. Mol Psychiatry. 2010; 15:80-92.

9. Barrientos RM. Voluntary exercise as an anti-neuroinflammatory therapeutic. Brain Behav Immun. $2011 ; 25: 1061-2$.

10. Colonna M, Butovsky O. Microglia Function in the Central Nervous System During Health and Neurodegeneration. Annu Rev Immunol. 2017; 35:441-68.

11. Niraula A, Sheridan JF, Godbout JP. Microglia Priming with Aging and Stress. Neuropsychopharmacology. 2017; 42:318-33.

12. Spangenberg EE, Green KN. Inflammation in Alzheimer's disease: Lessons learned from microgliadepletion models. Brain Behav Immun. 2017; 61:1-11.

13. Franco R, Fernandez-Suarez D. Alternatively activated microglia and macrophages in the central nervous system. Prog Neurobiol. 2015; 131:65-86.

14. Xiong XY, Liu L, Yang QW. Functions and mechanisms of microglia/macrophages in neuroinflammation and neurogenesis after stroke. Prog Neurobiol. 2016; 142:23-44.

15. Zhang J, Rong P, Zhang L, He H, Zhou T, Fan Y, Mo L, Zhao Q, Han Y, Li S, et al. IL4-driven microglia modulate stress resilience through BDNF-dependent neurogenesis. Sci Adv. 2021; 7.

16. Belarbi K, Arellano C, Ferguson R, Jopson T, Rosi S. Chronic neuroinflammation impacts the recruitment of adult-born neurons into behaviorally relevant hippocampal networks. Brain Behav Immun. 2012; 26:18-23.

17. Ekdahl CT, Claasen JH, Bonde S, Kokaia Z, Lindvall O. Inflammation is detrimental for neurogenesis in adult brain. Proc Natl Acad Sci U S A. 2003; 100:13632-7.

18. Gagic M, Jamroz E, Krizkova S, Milosavljevic V, Kopel P, Adam V. Current Trends in Detection of Histamine in Food and Beverages. J Agric Food Chem. 2019; 67:773-83.

19. Wada $\mathrm{H}$, Inagaki $\mathrm{N}$, Yamatodani A, Watanabe $\mathrm{T}$. Is the histaminergic neuron system a regulatory center for whole-brain activity? Trends Neurosci. 1991; 14:415-8.

20. Naddafi F, Mirshafiey A. The neglected role of histamine in Alzheimer's disease. Am J Alzheimers Dis Other Demen. 2013; 28:327-36.

21. Hu WW, Chen Z. Role of histamine and its receptors in cerebral ischemia. ACS Chem Neurosci. 2012; 3:238-47.

22. Liao RJ, Jiang L, Wang RR, Zhao HW, Chen Y, Li Y, Wang L, Jie LY, Zhou YD, Zhang XN, et al. Histidine provides long-term neuroprotection after cerebral ischemia through promoting astrocyte migration. Sci Rep. 2015; 5:15356.

23. Arrang JM, Garbarg M, Schwartz JC. Auto-inhibition of brain histamine release mediated by a novel class (H3) of histamine receptor. Nature. 1983; 302:832-7. 
24. Morisset S, Rouleau A, Ligneau X, Gbahou F, Tardivel-Lacombe J, Stark H, Schunack W, Ganellin CR, Schwartz JC, Arrang JM. High constitutive activity of native $\mathrm{H} 3$ receptors regulates histamine neurons in brain. Nature. 2000; 408:860-4.

25. Schlicker E, Betz R, Gothert M. Histamine H3 receptor-mediated inhibition of serotonin release in the rat brain cortex. Naunyn Schmiedebergs Arch Pharmacol. 1988; 337:588-90.

26. Schlicker E, Fink K, Hinterthaner M, Gothert M. Inhibition of noradrenaline release in the rat brain cortex via presynaptic H3 receptors. Naunyn Schmiedebergs Arch Pharmacol. 1989; 340:633-8.

27. Schlicker E, Fink K, Detzner M, Gothert M. Histamine inhibits dopamine release in the mouse striatum via presynaptic H3 receptors. J Neural Transm Gen Sect. 1993; 93:1-10.

28. Dai H, Fu Q, Shen Y, Hu W, Zhang Z, Timmerman H, Leurs R, Chen Z. The histamine H3 receptor antagonist clobenpropit enhances GABA release to protect against NMDA-induced excitotoxicity through the cAMP/protein kinase A pathway in cultured cortical neurons. Eur J Pharmacol. 2007; 563:117-23.

29. Hansen KB, Mullasseril P, Dawit S, Kurtkaya NL, Yuan H, Vance KM, Orr AG, Kvist T, Ogden KK, Le P, et al. Implementation of a fluorescence-based screening assay identifies histamine $\mathrm{H} 3$ receptor antagonists clobenpropit and iodophenpropit as subunit-selective N-methyl-D-aspartate receptor antagonists. J Pharmacol Exp Ther. 2010; 333:650-62.

30. Clapham J, Kilpatrick GJ. Histamine H3 receptors modulate the release of [3H]-acetylcholine from slices of rat entorhinal cortex: evidence for the possible existence of $\mathrm{H} 3$ receptor subtypes. $\mathrm{Br} \mathrm{J}$ Pharmacol. 1992; 107:919-23.

31. Medhurst AD, Atkins AR, Beresford IJ, Brackenborough K, Briggs MA, Calver AR, Cilia J, Cluderay JE, Crook B, Davis JB, et al. GSK189254, a novel H3 receptor antagonist that binds to histamine H3 receptors in Alzheimer's disease brain and improves cognitive performance in preclinical models. $J$ Pharmacol Exp Ther. 2007; 321:1032-45.

32. Brioni JD, Esbenshade TA, Garrison TR, Bitner SR, Cowart MD. Discovery of histamine H3 antagonists for the treatment of cognitive disorders and Alzheimer's disease. J Pharmacol Exp Ther. 2011; 336:38-46.

33. Bitner RS, Markosyan S, Nikkel AL, Brioni JD. In-vivo histamine H3 receptor antagonism activates cellular signaling suggestive of symptomatic and disease modifying efficacy in Alzheimer's disease. Neuropharmacology. 2011; 60:460-6.

34. Patnaik R, Sharma A, Skaper SD, Muresanu DF, Lafuente JV, Castellani RJ, Nozari A, Sharma HS. Histamine H3 Inverse Agonist BF 2649 or Antagonist with Partial H4 Agonist Activity Clobenpropit Reduces Amyloid Beta Peptide-Induced Brain Pathology in Alzheimer's Disease. Mol Neurobiol. 2018; 55:312-21.

35. Wang J, Liu B, Xu Y, Yang M, Wang C, Song M, Liu J, Wang W, You J, Sun F, et al. Activation of CREBmediated autophagy by thioperamide ameliorates beta-amyloid pathology and cognition in Alzheimer's disease. Aging Cell. 2021; 20:e13333. 
36. Guilloux JP, Samuels BA, Mendez-David I, Hu A, Levinstein M, Faye C, Mekiri M, Mocaer E, Gardier AM, Hen R, et al. S 38093, a histamine H3 antagonist/inverse agonist, promotes hippocampal neurogenesis and improves context discrimination task in aged mice 1. Sci Rep. 2017; 7:42946.

37. Wang J, Liu B, Xu Y, Luan H, Wang C, Yang M, Zhao R, Song M, Liu J, Sun L, et al. Thioperamide attenuates neuroinflammation and cognitive impairments in Alzheimer's disease via inhibiting gliosis. Experimental Neurology. 2021.

38. Eissa N, Jayaprakash P, Azimullah S, Ojha SK, Al-Houqani M, Jalal FY, Lazewska D, Kiec-Kononowicz K, Sadek B. The histamine H3R antagonist DL77 attenuates autistic behaviors in a prenatal valproic acid-induced mouse model of autism. Sci Rep. 2018; 8:13077.

39. Hiraga N, Adachi N, Liu K, Nagaro T, Arai T. Suppression of inflammatory cell recruitment by histamine receptor stimulation in ischemic rat brains. Eur J Pharmacol. 2007; 557:236-44.

40. Saraiva C, Barata-Antunes S, Santos T, Ferreiro E, Cristovao AC, Serra-Almeida C, Ferreira R, Bernardino L. Histamine modulates hippocampal inflammation and neurogenesis in adult mice. Sci Rep. 2019; 9:8384.

41. Bernardino L, Eiriz MF, Santos T, Xapelli S, Grade S, Rosa Al, Cortes L, Ferreira R, Braganca J, Agasse F, et al. Histamine stimulates neurogenesis in the rodent subventricular zone. Stem Cells. 2012; 30:773-84.

42. Rangon CM, Schang AL, Van Steenwinckel J, Schwendimann L, Lebon S, Fu T, Chen L, Beneton V, Journiac N, Young-Ten P, et al. Myelination induction by a histamine $\mathrm{H} 3$ receptor antagonist in a mouse model of preterm white matter injury. Brain Behav Immun. 2018; 74:265-76.

43. Liao R, Chen Y, Cheng L, Fan L, Chen H, Wan Y, You Y, Zheng Y, Jiang L, Chen Z, et al. Histamine H1 Receptors in Neural Stem Cells Are Required for the Promotion of Neurogenesis Conferred by H3 Receptor Antagonism following Traumatic Brain Injury. Stem Cell Reports. 2019; 12:532-44.

44. Wang N, Ma J, Liu J, Wang J, Liu C, Wang H, Liu Y, Yan H, Jiang S. Histamine H3 Receptor Antagonist Enhances Neurogenesis and Improves Chronic Cerebral Hypoperfusion-Induced Cognitive Impairments. Front Pharmacol. 2020; 10.

45. Morini G, Grandi D, Schunack W. Ligands for histamine $H(3)$ receptors modulate cell proliferation and migration in rat oxyntic mucosa. Br J Pharmacol. 2002; 137:237-44.

46. Liu B, Liu J, Wang J, Liu C, Yan H. AdipoRon improves cognitive dysfunction of Alzheimer's disease and rescues impaired neural stem cell proliferation through AdipoR1/AMPK pathway. Exp Neurol. 2020:113249.

47. Yan H, Zhang X, Hu W, Ma J, Hou W, Zhang X, Wang X, Gao J, Shen Y, Lv J, et al. Histamine H3 receptors aggravate cerebral ischaemic injury by histamine-independent mechanisms. Nat Commun. 2014; 5:3334.

48. Gruneberg D, Montellano FA, Plaschke K, Li L, Marti HH, Kunze R. Neuronal prolyl-4-hydroxylase 2 deficiency improves cognitive abilities in a murine model of cerebral hypoperfusion. Exp Neurol. 2016; 286:93-106. 
49. Wang H, Warner-Schmidt J, Varela S, Enikolopov G, Greengard P, Flajolet M. Norbin ablation results in defective adult hippocampal neurogenesis and depressive-like behavior in mice. Proc Natl Acad Sci U S A. 2015; 112:9745-50.

50. Liu B, Liu J, Wang J, Sun F, Jiang S, Hu F, Wang D, Liu D, Liu C, Yan H. Adiponectin Protects Against Cerebral Ischemic Injury Through AdipoR1/AMPK Pathways. Front Pharmacol. 2019; 10:597.

51. Chiba T, Yamada M, Sasabe J, Terashita K, Shimoda M, Matsuoka M, Aiso S. Amyloid-beta causes memory impairment by disturbing the JAK2/STAT3 axis in hippocampal neurons. Mol Psychiatry. 2009; 14:206-22.

52. Vorhees CV, Williams MT. Morris water maze: procedures for assessing spatial and related forms of learning and memory. Nature Protocols. 2006; 1:848-58.

53. Ferreira R, Santos T, Goncalves J, Baltazar G, Ferreira L, Agasse F, Bernardino L. Histamine modulates microglia function. J Neuroinflammation. 2012; 9:90.

54. Cohen J. The immunopathogenesis of sepsis. Nature. 2002; 420:885-91.

55. Rivest S. Molecular insights on the cerebral innate immune system. Brain Behav Immun. 2003; 17:139.

56. Liddelow SA, Guttenplan KA, Clarke LE, Bennett FC, Bohlen CJ, Schirmer L, Bennett ML, Munch AE, Chung WS, Peterson TC, et al. Neurotoxic reactive astrocytes are induced by activated microglia. Nature. 2017; 541:481-7.

57. Pekny $M$, Wilhelmsson $U$, Pekna M. The dual role of astrocyte activation and reactive gliosis. Neurosci Lett. 2014; 565:30-8.

58. Littlefield AM, Setti SE, Priester C, Kohman RA. Voluntary exercise attenuates LPS-induced reductions in neurogenesis and increases microglia expression of a proneurogenic phenotype in aged mice. $J$ Neuroinflammation. 2015; 12:138.

59. Liu Y, Zhang Y, Zheng X, Fang T, Yang X, Luo X, Guo A, Newell KA, Huang XF, Yu Y. Galantamine improves cognition, hippocampal inflammation, and synaptic plasticity impairments induced by lipopolysaccharide in mice. J Neuroinflammation. 2018; 15:112.

60. Passani MB, Bacciottini L, Mannaioni PF, Blandina P. Central histaminergic system and cognition. Neurosci Biobehav Rev. 2000; 24:107-13.

61. Flamand N, Plante H, Picard S, Laviolette M, Borgeat P. Histamine-induced inhibition of leukotriene biosynthesis in human neutrophils: involvement of the $\mathrm{H} 2$ receptor and CAMP. Br J Pharmacol. 2004; 141:552-61.

62. Gao C, Major A, Rendon D, Lugo M, Jackson V, Shi Z, Mori-Akiyama Y, Versalovic J. Histamine H2 Receptor-Mediated Suppression of Intestinal Inflammation by Probiotic Lactobacillus reuteri. mBio. 2015; 6:e01358-15.

63. Park T, Chen H, Kevala K, Lee JW, Kim HY. N-Docosahexaenoylethanolamine ameliorates LPSinduced neuroinflammation via cAMP/PKA-dependent signaling. J Neuroinflammation. 2016; $13: 284$. 
64. Wen AY, Sakamoto KM, Miller LS. The role of the transcription factor CREB in immune function. J Immunol. 2010; 185:6413-9.

65. Coudriet GM, He J, Trucco M, Mars WM, Piganelli JD. Hepatocyte growth factor modulates interleukin-6 production in bone marrow derived macrophages: implications for inflammatory mediated diseases. PLoS One. 2010; 5:e15384.

66. Jones KR, Kang EM. Graft versus host disease: New insights into A2A receptor agonist therapy. Comput Struct Biotechnol J. 2015; 13:101-5.

67. Ortega-Martinez S. A new perspective on the role of the CREB family of transcription factors in memory consolidation via adult hippocampal neurogenesis. Front Mol Neurosci. 2015; 8:46.

68. Zhu DY, Lau L, Liu SH, Wei JS, Lu YM. Activation of cAMP-response-element-binding protein (CREB) after focal cerebral ischemia stimulates neurogenesis in the adult dentate gyrus. Proc Natl Acad Sci U S A. 2004; 101:9453-7.

69. Zhang G, Zhang T, Li N, Wu L, Gu J, Li C, Zhao C, Liu W, Shan L, Yu P, et al. Tetramethylpyrazine nitrone activates the BDNF/Akt/CREB pathway to promote post-ischaemic neuroregeneration and recovery of neurological functions in rats. Br J Pharmacol. 2018; 175:517-31.

70. Xia W, Liu Y, Jiao J. GRM7 regulates embryonic neurogenesis via CREB and YAP. Stem Cell Reports. $2015 ; 4: 795-810$.

71. Merz K, Herold S, Lie DC. CREB in adult neurogenesis--master and partner in the development of adult-born neurons? Eur J Neurosci. 2011; 33:1078-86.

72. Zlomuzica A, Dere D, Binder S, De Souza Silva MA, Huston JP, Dere E. Neuronal histamine and cognitive symptoms in Alzheimer's disease. Neuropharmacology. 2016; 106:135-45.

73. Valero J, Mastrella G, Neiva I, Sanchez S, Malva JO. Long-term effects of an acute and systemic administration of LPS on adult neurogenesis and spatial memory. Front Neurosci. 2014; 8:83.

74. Zhao W, Xu Z, Cao J, Fu Q, Wu Y, Zhang X, Long Y, Zhang X, Yang Y, Li Y, Mi W. Elamipretide (SS-31) improves mitochondrial dysfunction, synaptic and memory impairment induced by lipopolysaccharide in mice. J Neuroinflammation. 2019; 16:230.

75. Ransohoff RM. How neuroinflammation contributes to neurodegeneration. Science. 2016; 353:77783.

76. Marschallinger J, Iram T, Zardeneta M, Lee SE, Lehallier B, Haney MS, Pluvinage JV, Mathur V, Hahn $\mathrm{O}$, Morgens DW, et al. Lipid-droplet-accumulating microglia represent a dysfunctional and proinflammatory state in the aging brain. Nat Neurosci. 2020; 23:194-208.

77. Sarlus H, Heneka MT. Microglia in Alzheimer's disease. J Clin Invest. 2017; 127:3240-9.

78. Di Meco A, Curtis ME, Lauretti E, Pratico D. Autophagy Dysfunction in Alzheimer's Disease: Mechanistic Insights and New Therapeutic Opportunities. Biol Psychiatry. 2020; 87:797-807.

79. Shan L, Bao AM, Swaab DF. The human histaminergic system in neuropsychiatric disorders. Trends Neurosci. 2015; 38:167-77. 
80. lida T, Yoshikawa T, Karpati A, Matsuzawa T, Kitano H, Mogi A, Harada R, Naganuma F, Nakamura T, Yanai K. JNJ10181457, a histamine H3 receptor inverse agonist, regulates in vivo microglial functions and improves depression-like behaviours in mice. Biochem Biophys Res Commun. 2017; 488:534-40.

81. lida T, Yoshikawa T, Matsuzawa T, Naganuma F, Nakamura T, Miura Y, Mohsen AS, Harada R, Iwata R, Yanai K. Histamine $\mathrm{H} 3$ receptor in primary mouse microglia inhibits chemotaxis, phagocytosis, and cytokine secretion. Glia. 2015; 63:1213-25.

82. Tang Y, Le W. Differential Roles of M1 and M2 Microglia in Neurodegenerative Diseases. Molecular Neurobiology. 2015; 53:1181-94.

83. Frick L, Rapanelli M, Abbasi E, Ohtsu H, Pittenger C. Histamine regulation of microglia: Geneenvironment interaction in the regulation of central nervous system inflammation. Brain Behav Immun. 2016; 57:326-37.

84. Dong $H$, Zhang W, Zeng $X, H u ~ G$, Zhang $H$, He S, Zhang S. Histamine induces upregulated expression of histamine receptors and increases release of inflammatory mediators from microglia. Mol Neurobiol. 2014; 49:1487-500.

85. Rocha SM, Saraiva T, Cristovao AC, Ferreira R, Santos T, Esteves M, Saraiva C, Je G, Cortes L, Valero $\mathrm{J}$, et al. Histamine induces microglia activation and dopaminergic neuronal toxicity via $\mathrm{H} 1$ receptor activation. J Neuroinflammation. 2016; 13:137.

86. Barata-Antunes S, Cristovao AC, Pires J, Rocha SM, Bernardino L. Dual role of histamine on microglia-induced neurodegeneration. Biochim Biophys Acta Mol Basis Dis. 2017; 1863:764-9.

87. Zhang W, Zhang X, Zhang Y, Qu C, Zhou X, Zhang S. Histamine Induces Microglia Activation and the Release of Proinflammatory Mediators in Rat Brain Via H1R or H4R. J Neuroimmune Pharmacol. 2019.

88. Molina-Hernandez A, Velasco I. Histamine induces neural stem cell proliferation and neuronal differentiation by activation of distinct histamine receptors. J Neurochem. 2008; 106:706-17.

89. Ambree O, Buschert J, Zhang W, Arolt V, Dere E, Zlomuzica A. Impaired spatial learning and reduced adult hippocampal neurogenesis in histamine H1-receptor knockout mice. Eur Neuropsychopharmacol. 2014; 24:1394-404.

90. Monje ML, Toda H, Palmer TD. Inflammatory blockade restores adult hippocampal neurogenesis. Science. 2003; 302:1760-5.

91. Belenguer G, Duart-Abadia P, Jordan-Pla A, Domingo-Muelas A, Blasco-Chamarro L, Ferron SR, Morante-Redolat JM, Farinas I. Adult Neural Stem Cells Are Alerted by Systemic Inflammation through TNF-alpha Receptor Signaling. Cell Stem Cell. 2021; 28:285-99 e9.

92. Eissa N, Sadeq A, Sasse A, Sadek B. Role of Neuroinflammation in Autism Spectrum Disorder and the Emergence of Brain Histaminergic System. Lessons Also for BPSD? Front Pharmacol. 2020; 11:886.

93. Saura CA, Cardinaux JR. Emerging Roles of CREB-Regulated Transcription Coactivators in Brain Physiology and Pathology. Trends Neurosci. 2017; 40:720-33. 
94. Dineley KT, Westerman M, Bui D, Bell K, Ashe KH, Sweatt JD. Beta-amyloid activates the mitogenactivated protein kinase cascade via hippocampal alpha7 nicotinic acetylcholine receptors: In vitro and in vivo mechanisms related to Alzheimer's disease. J Neurosci. 2001; 21:4125-33.

95. Chen TT, Lan TH, Yang FY. Low-Intensity Pulsed Ultrasound Attenuates LPS-Induced Neuroinflammation and Memory Impairment by Modulation of TLR4/NF-kappaB Signaling and CREB/BDNF Expression. Cereb Cortex. 2019; 29:1430-8.

96. Hladik D, Dalke C, von Toerne C, Hauck SM, Azimzadeh O, Philipp J, Ung MC, Schlattl H, Rossler U, Graw J, et al. CREB Signaling Mediates Dose-Dependent Radiation Response in the Murine Hippocampus Two Years after Total Body Exposure. J Proteome Res. 2020; 19:337-45.

97. Hong ZY, Yu SS, Wang ZJ, Zhu YZ. SCM-198 Ameliorates Cognitive Deficits, Promotes Neuronal Survival and Enhances CREB/BDNF/TrkB Signaling without Affecting Abeta Burden in AbetaPP/PS1 Mice. Int J Mol Sci. 2015; 16:18544-63.

98. Luan B, Yoon YS, Le Lay J, Kaestner KH, Hedrick S, Montminy M. CREB pathway links PGE2 signaling with macrophage polarization. Proc Natl Acad Sci U S A. 2015; 112:15642-7.

99. Alexaki VI, Fodelianaki G, Neuwirth A, Mund C, Kourgiantaki A, leronimaki E, Lyroni K, Troullinaki M, Fujii C, Kanczkowski W, et al. DHEA inhibits acute microglia-mediated inflammation through activation of the TrkA-Akt1/2-CREB-Jmjd3 pathway. Mol Psychiatry. 2018; 23:1410-20.

100. Leurs R, Bakker RA, Timmerman $H$, de Esch IJ. The histamine $H 3$ receptor: from gene cloning to $H 3$ receptor drugs. Nat Rev Drug Discov. 2005; 4:107-20.

101. Kaltschmidt B. NF-kB in the nervous system. Nuclear Factor Kb Regulation \& Role in Disease. 2003.

102. Wu X, Fu S, Liu Y, Luo H, Li F, Wang Y, Gao M, Cheng Y, Xie Z. NDP-MSH binding melanocortin-1 receptor ameliorates neuroinflammation and BBB disruption through CREB/Nr4a1/NF-kappaB pathway after intracerebral hemorrhage in mice. J Neuroinflammation. 2019; 16:192.

103. Zhang S, Xu W, Wang H, Cao M, Li M, Zhao J, Hu Y, Wang Y, Li S, Xie Y, et al. Inhibition of CREBmediated ZO-1 and activation of NF-kappaB-induced IL- 6 by colonic epithelial MCT4 destroys intestinal barrier function. Cell Prolif. 2019; 52:e12673.

\section{Figures}




\section{A}
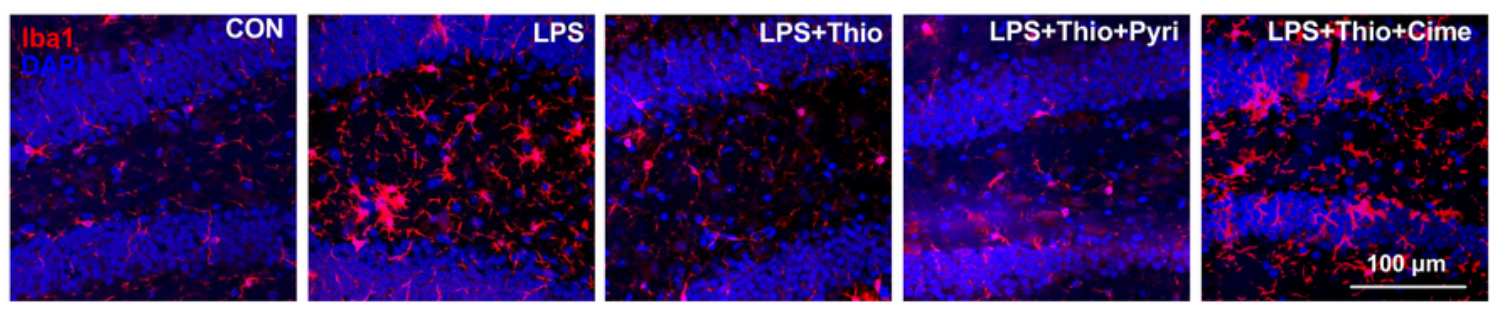

B

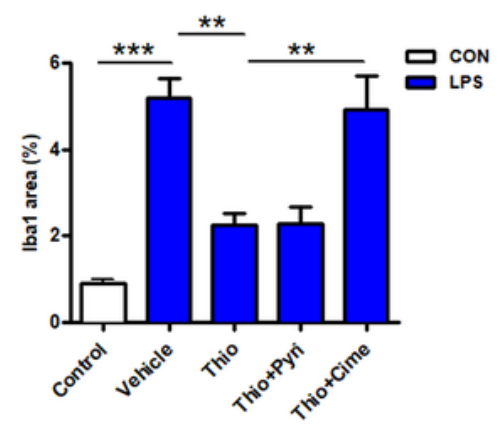

C

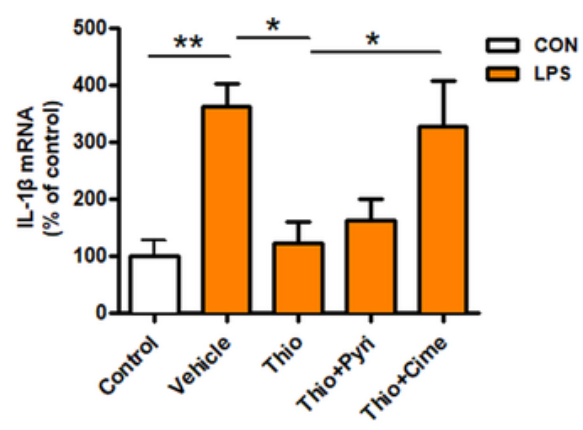

D

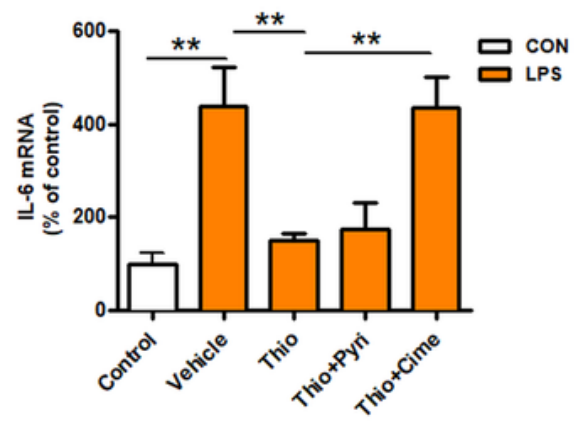

E

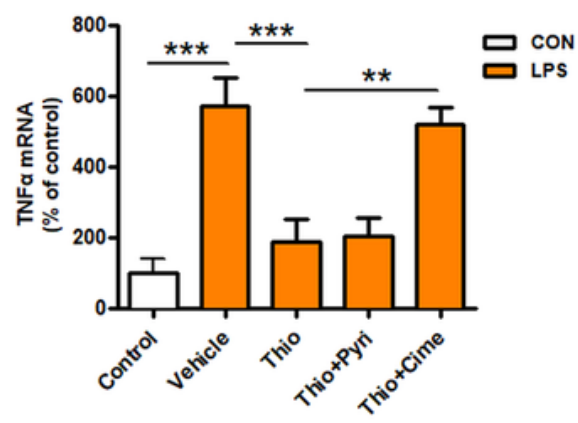

F

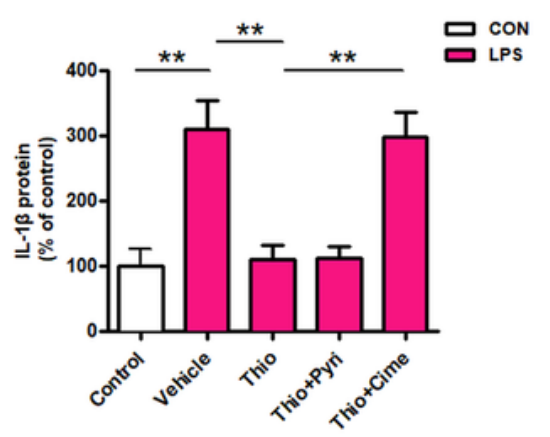

G

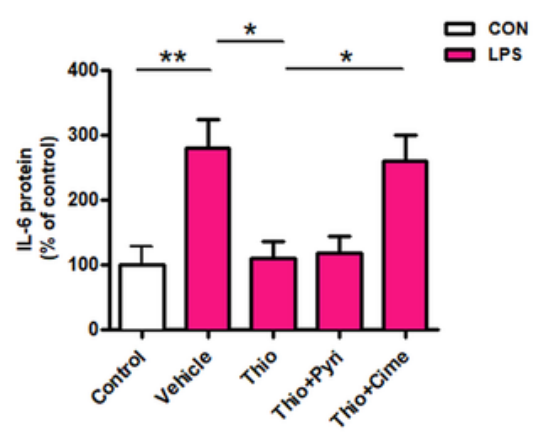

$\mathrm{H}$

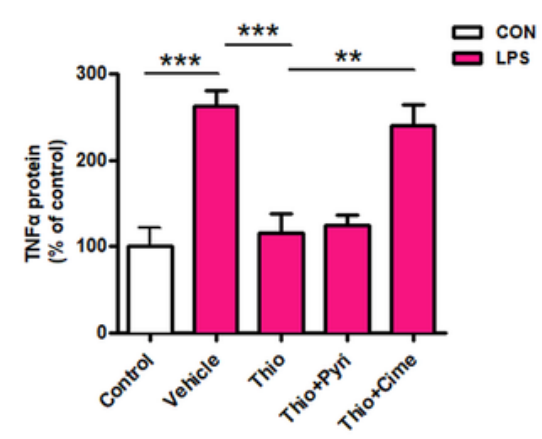

\section{Figure 1}

Effects of thioperamide and histamine receptor antagonists on microglial reactivity and proinflammatory cytokines production in LPS treated mice. (A-B) Representative immunohistochemical staining of Iba1 (red) (A) and bar graph (B) in hippocampal DG showing the Iba1+ microglial reactivity in those receiving vehicle, thioperamide, pyrilamine and cimetidine in LPS treated mice. Scale bar: $100 \mu \mathrm{m}$. (C-E) Transcriptional levels of IL-1 (C), IL-6 (D) and TNF-a (E) in the hippocampal DG were measured via RT- 
PCR in those receiving vehicle, thioperamide, pyrilamine and cimetidine in LPS treated mice. (F-H) Protein levels of IL-1 $\beta(F)$, IL-6 (G) and TNF- $\alpha(H)$ in the hippocampal DG were measured via ELISA in those receiving vehicle, thioperamide, pyrilamine and cimetidine in LPS treated mice. $n=5$ per group. ${ }^{*}<<0.05$, $* * \mathrm{P}<0.01,{ }^{* * *} \mathrm{P}<0.001$. Mean \pm SEM. One-way ANOVA followed by Tukey's post hoc test.

A
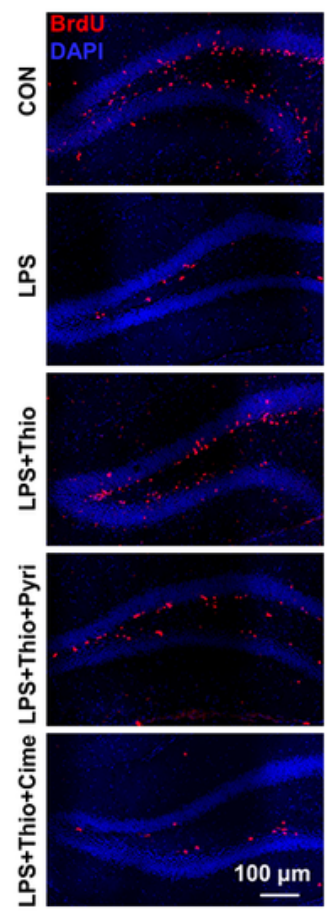

$\mathrm{D}$
B
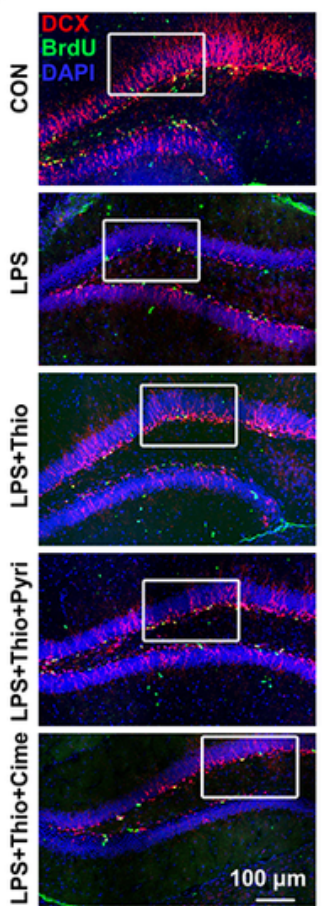

$\mathrm{E}$
C
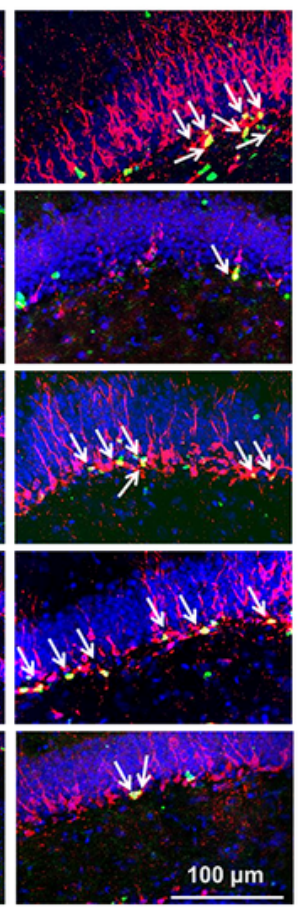
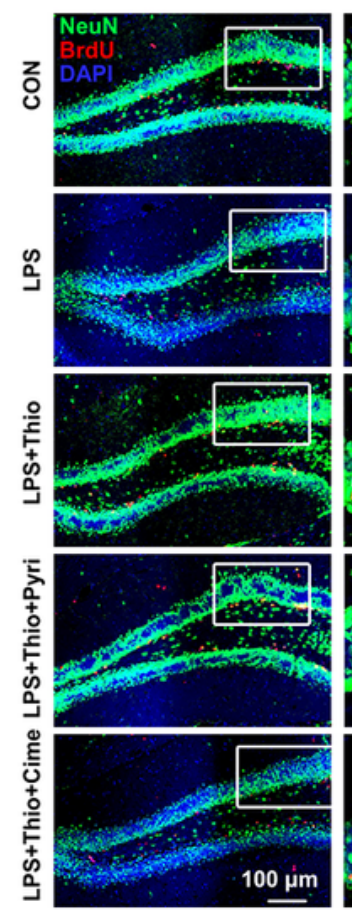

F
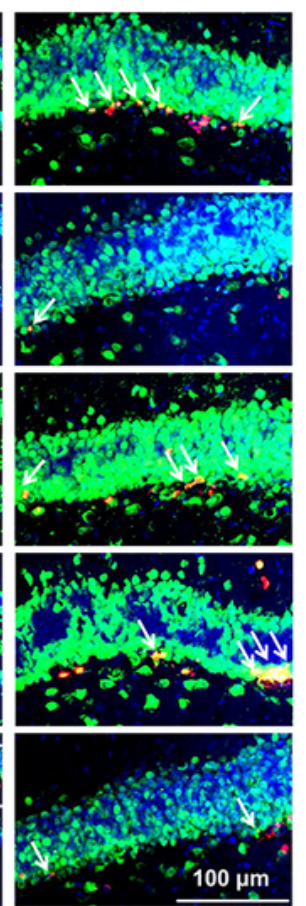

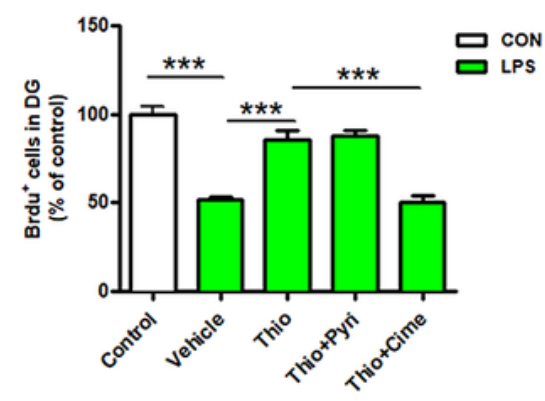

G

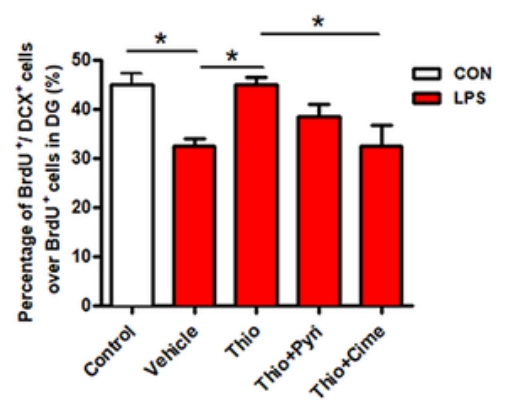

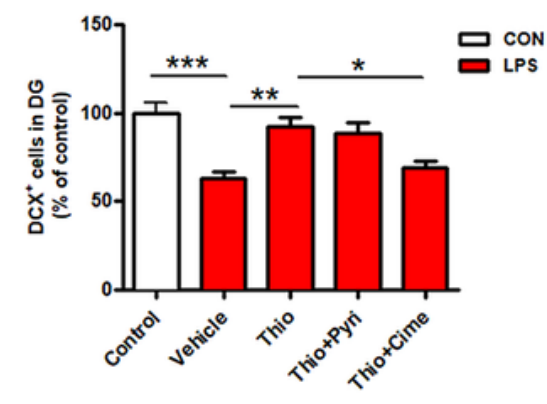

$\mathrm{H}$

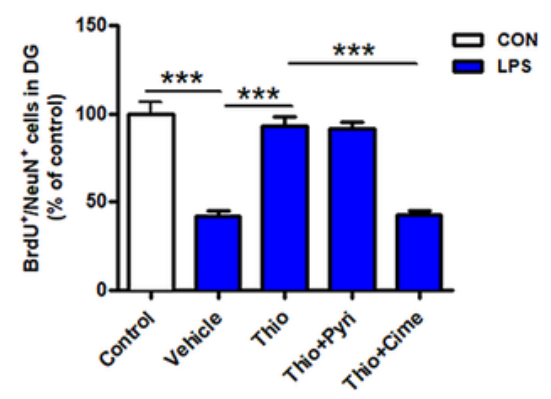

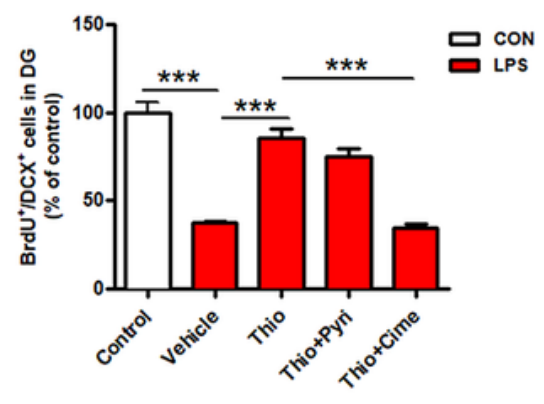

I

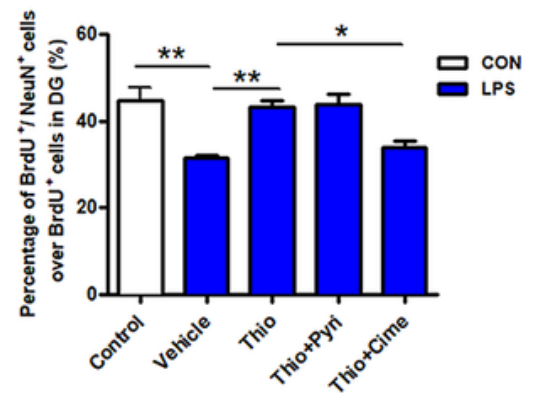

Figure 2 
Effects of thioperamide and histamine receptor antagonists on neurogenesis in LPS treated mice. (A, D) The immunohistochemical staining of BrdU (Red) (A) and bar graph (D) in hippocampus DG region showing the effects of thioperamide, pyrilamine and cimetidine on BrdU-positive newborn cells in DG in LPS treated mice. Scale bar: $100 \mu \mathrm{m}$. (B, E-G) The co-immunohistochemical staining of BrdU (Green) and DCX (Red) (B) and bar graph (E-G) in hippocampus DG region showing the effects of thioperamide, pyrilamine and cimetidine on DCX- $(E)$ and $\operatorname{BrdU/DCX}-(F, G)$ positive newborn cells in DG in LPS treated mice. Scale bar: $100 \mu \mathrm{m}$. (C, H, I) The co-immunohistochemical staining of BrdU (Red) and NeuN (Green) (C) and bar graph $(H, I)$ in hippocampus DG region showing the effects of thioperamide, pyrilamine and cimetidine on BrdU/DCX-positive newborn cells $(H, I)$ in DG in LPS treated mice. $n=5$ per group. ${ }^{*} P<0.05$, ${ }^{\star} \mathrm{P}<0.01,{ }^{\star * \star} \mathrm{P}<0.001$. Mean $\pm \mathrm{SEM}$. One-way ANOVA followed by Tukey's post hoc test.

A
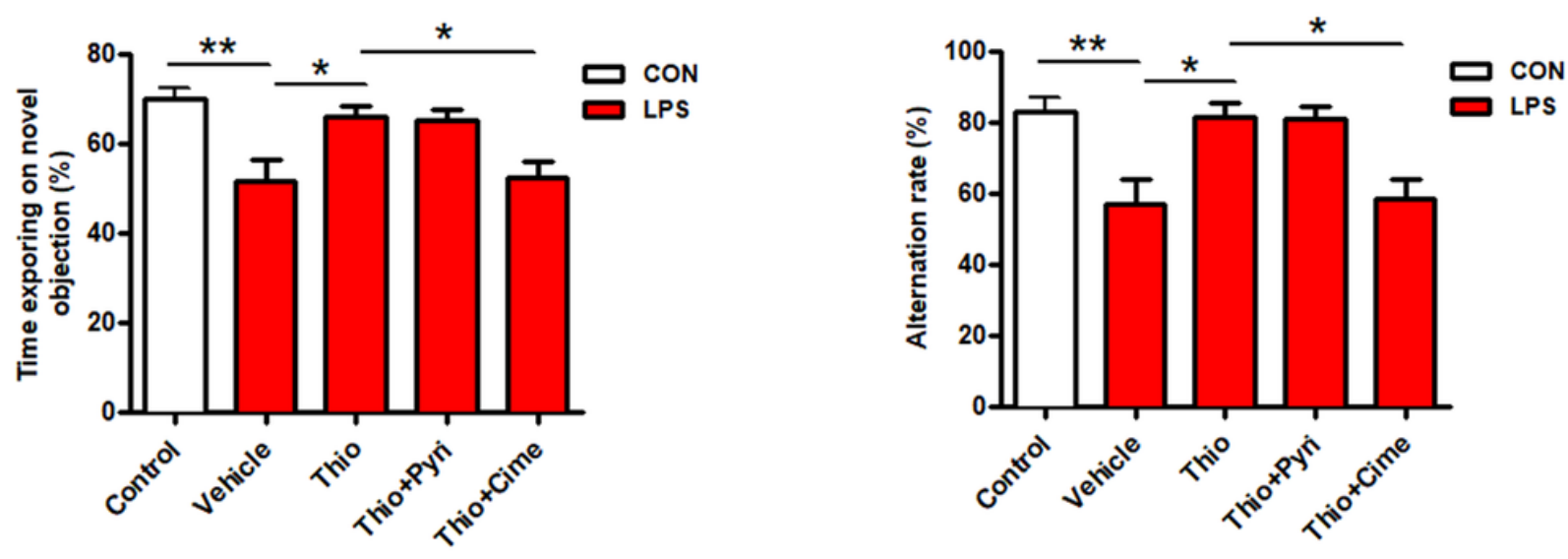

C
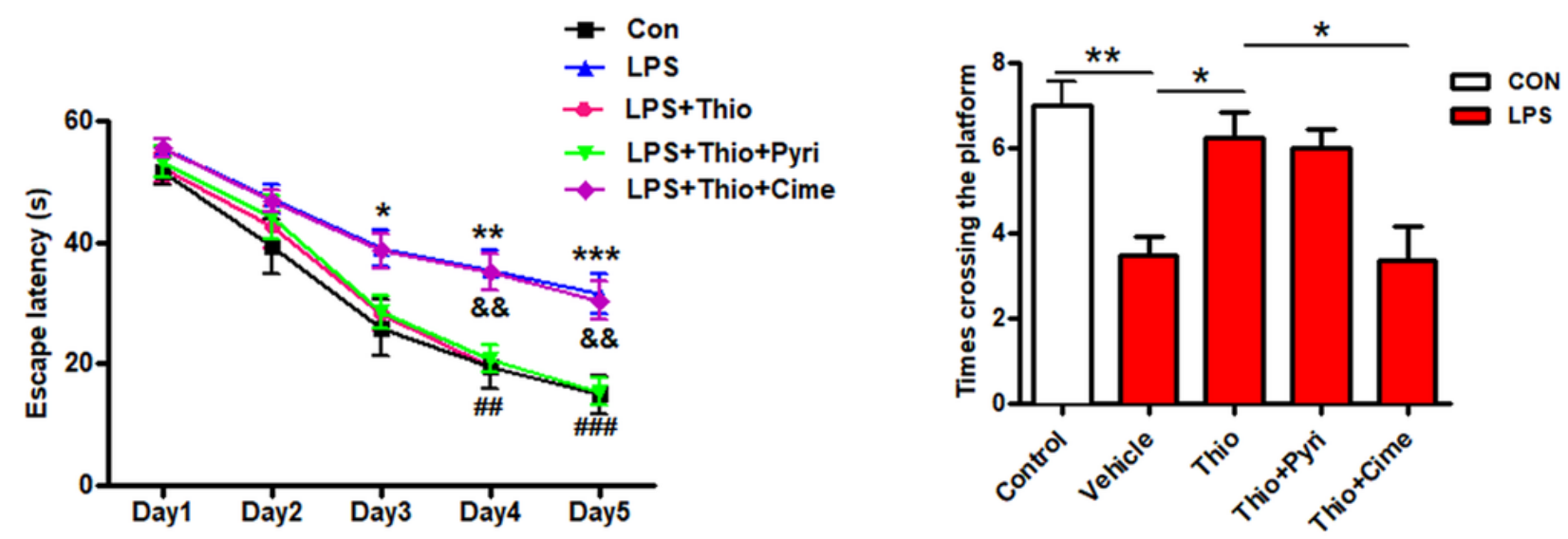

Figure 3 
Effects of thioperamide and histamine receptor antagonists on cognitive function in LPS treated mice. (A) The NOR test showing effects of thioperamide, pyrilamine and cimetidine on the exploring time on new object in LPS treated mice. (B) The Y maze test showing the alternation rate in those receiving vehicle, thioperamide, pyrilamine and cimetidine in LPS treated mice. (C, D) The MWM test showing the escape latency on training days (C) and crossing times on testing day (D) in those receiving vehicle, thioperamide, pyrilamine and cimetidine in LPS treated mice. $n=8$ per group. ${ }^{\star} P<0.05,{ }^{\star \star} P<0.01$ in $A, B$

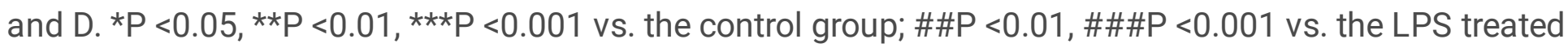
group; \&\&P $<0.01$ vs. the thioperamide treated group in group in $\mathrm{C}$. Mean $\pm \mathrm{SEM}$. One-way ANOVA followed by Tukey's post hoc (A, B and D) and two-way ANOVA followed by Bonferroni post hoc test (C). 
A

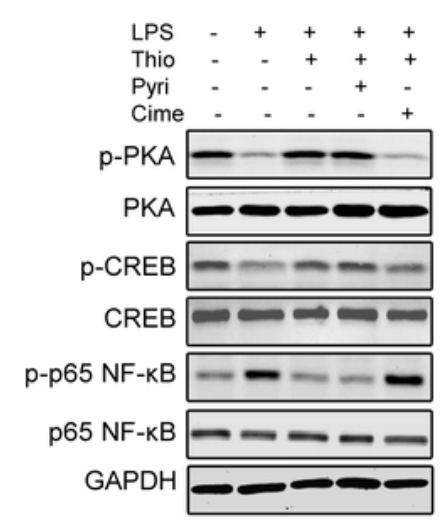

B

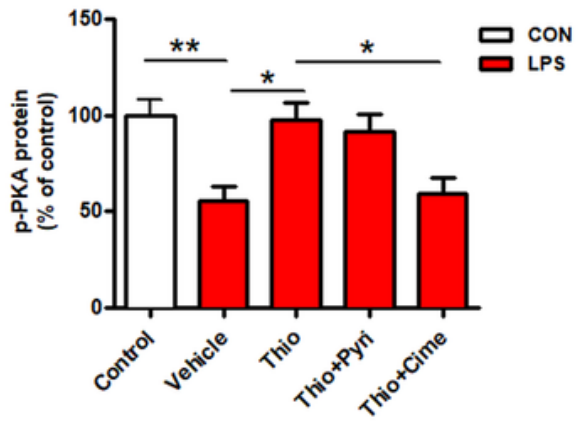

C

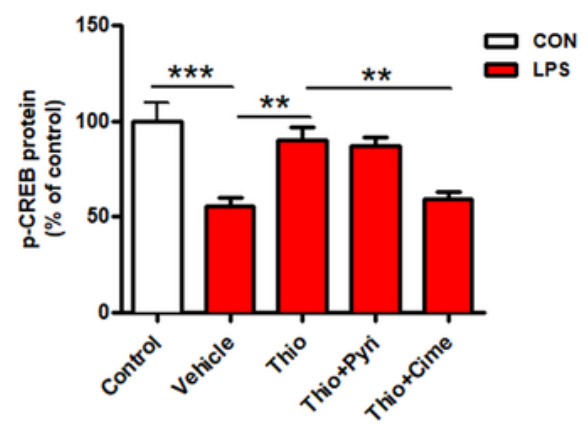

D

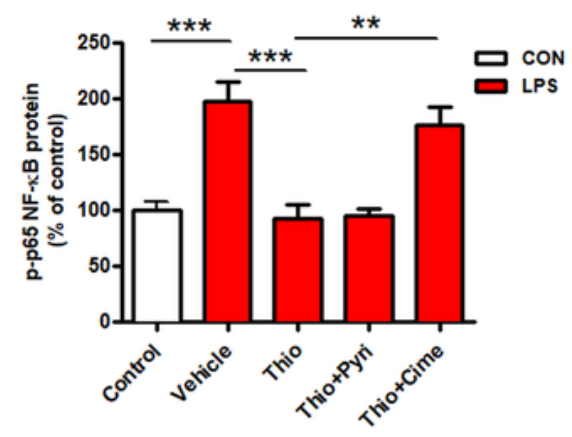

E

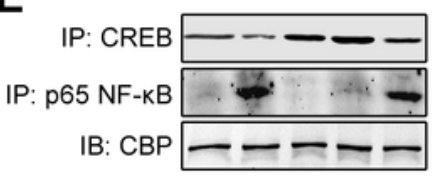

$\mathbf{F}$

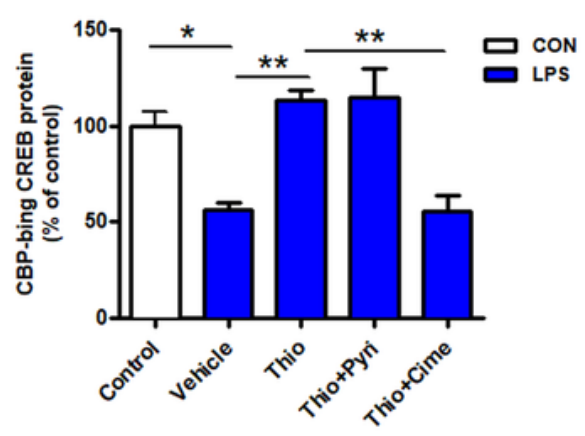

G

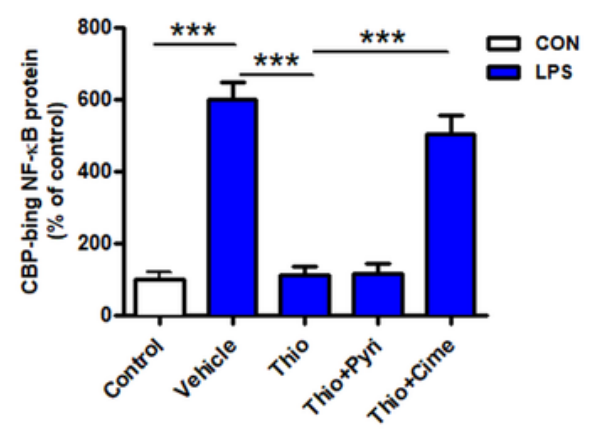

\section{Figure 4}

Effects of thioperamide and histamine receptor antagonists on PKA/CREB and NF-KB pathway in LPS treated mice. (A-D) Representative Western blots (A) and bar graph (B-D) showing the effect of thioperamide, pyrilamine and cimetidine on expression of p-PKA (B), p-CREB (C) and p-P65 NF-KB (D) in hippocampus in LPS treated mice. (E-G) Representative co-immunoprecipitation results (E) showing the effect of thioperamide, pyrilamine and cimetidine on interaction of CREB-CBP (F) and NF-KB-CBP $(G)$ in 
hippocampus in LPS treated mice. $n=5$ per group. ${ }^{*} P<0.05,{ }^{\star} P<0.01,{ }^{\star} * \star P<0.001$. Mean \pm SEM. Oneway ANOVA followed by Tukey's post hoc test.

A

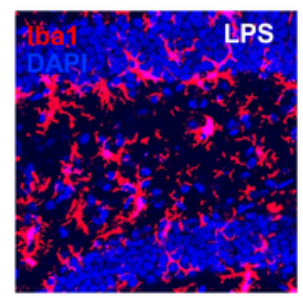

C

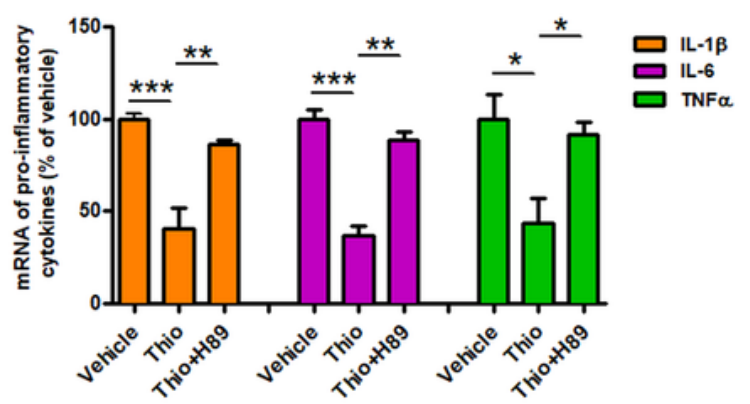

E

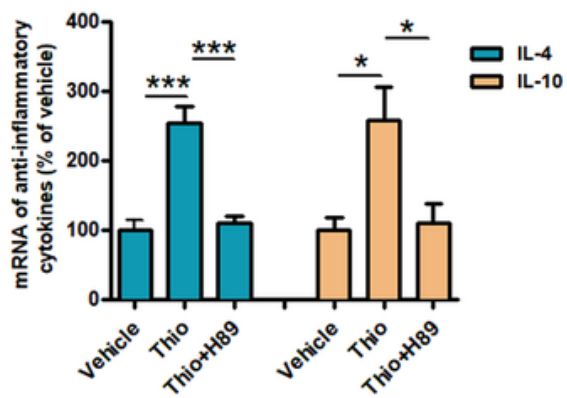

G

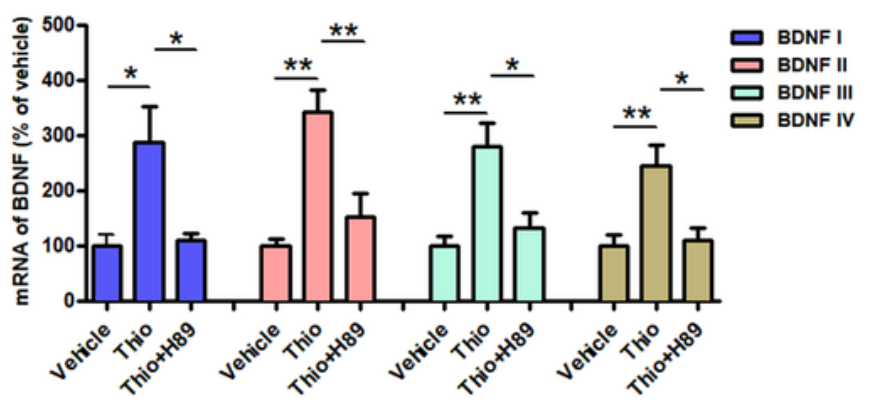

B

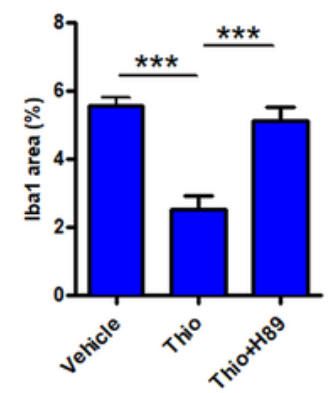

$\mathrm{F}$
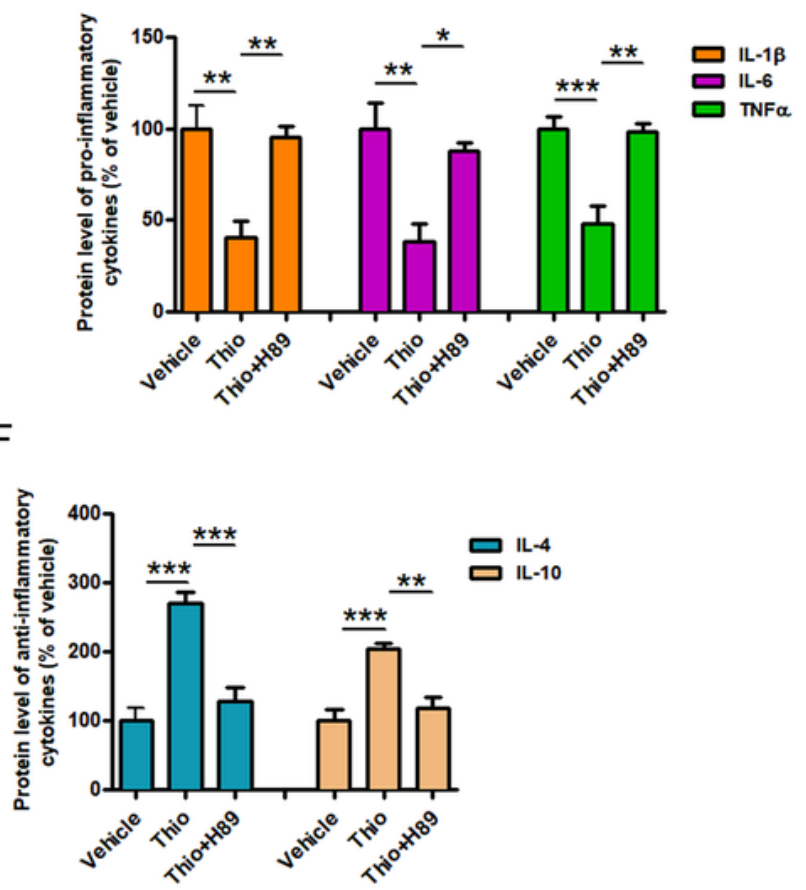

$\mathrm{H}$

\section{Figure 5}

H89 reverses the decreased microglia reactivity and anti-inflammatory response by thioperamide in LPS treated mice. (A, B) Representative immunohistochemical staining of Iba1 (red) (A) and bar graph (B) in hippocampal DG showing the Iba1+ microglial reactivity in those receiving vehicle, thioperamide, and $\mathrm{H} 89$ 
in LPS treated mice. Scale bar: $100 \mu \mathrm{m}$. (C, D) mRNA levels (C) and protein levels (D) of pro-inflammatory cytokines including IL-1 $\beta$, IL- 6 and TNF- $\alpha$ in the hippocampal DG were measured by RT-PCR (C) and ELISA (D) in those receiving vehicle, thioperamide and H89 in LPS treated mice. (E, F) mRNA levels (E) and protein levels (F) of anti-inflammatory cytokines including IL-14 and IL-10 in the hippocampal DG were measured by RT-PCR (E) and ELISA (F) in those receiving vehicle, thioperamide and H89 in LPS treated mice. $(G, H)$ mRNA levels $(G)$ and protein levels $(H)$ of neurotrophic factor BDNF in the hippocampal DG were measured by RT-PCR $(G)$ and ELISA $(H)$ in those receiving vehicle, thioperamide and H89 in LPS treated mice. $n=5$ per group. ${ }^{\star} P<0.05,{ }^{\star} \mathrm{P}<0.01$, ${ }^{\star \star \star} \mathrm{P}<0.001$. Mean $\pm \mathrm{SEM}$. One-way ANOVA followed by Tukey's post hoc test. 


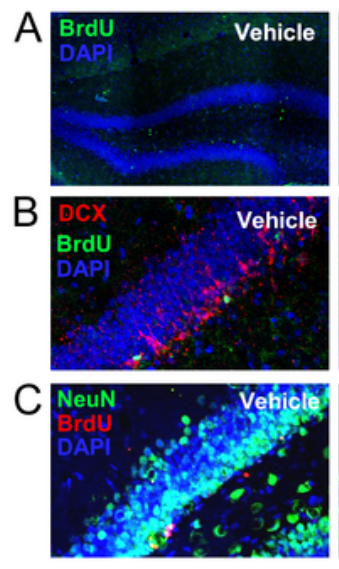

D

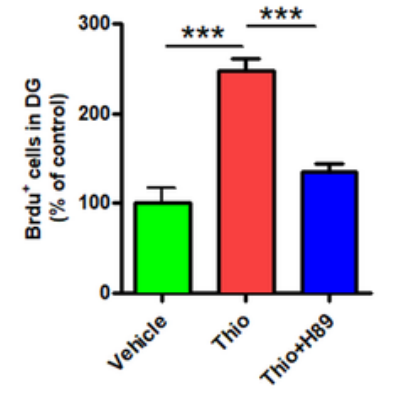

$\mathrm{F}$

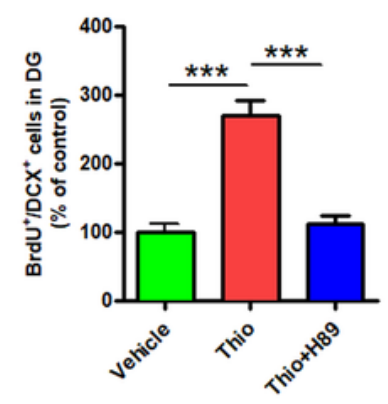

$\mathrm{H}$

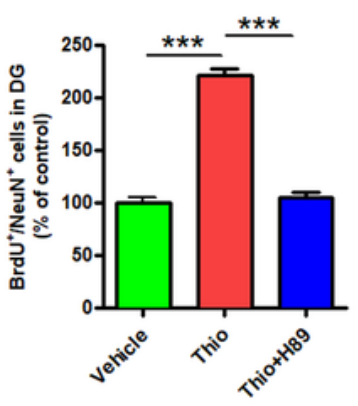

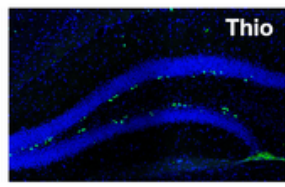
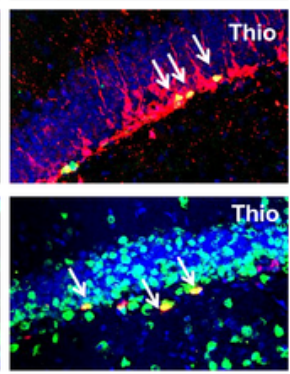

E

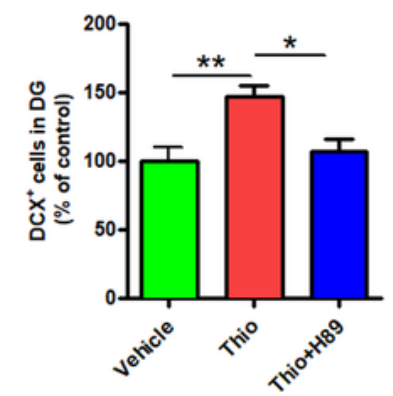

G
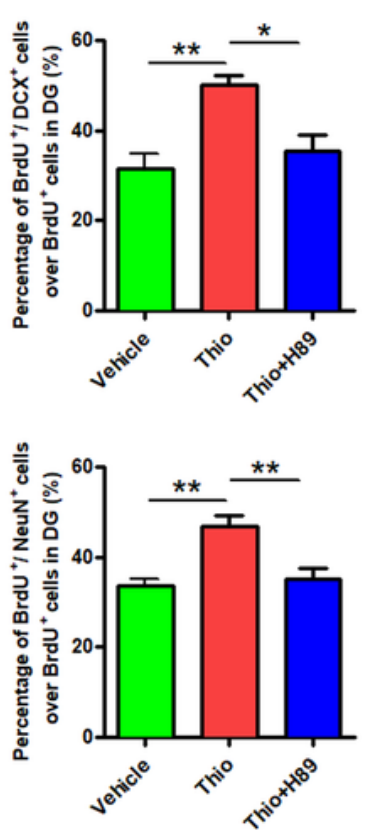

\section{Figure 6}

H89 reverses the enhanced neurogenesis offered by thioperamide in LPS treated mice. (A, D) The immunohistochemical staining of BrdU (Green) (A) and bar graph (D) in hippocampus DG region showing the effects of thioperamide and $\mathrm{H} 89$ on BrdU-positive newborn cells in DG of hippocampus in LPS treated mice. Scale bar: $100 \mu \mathrm{m}$. (B, E-G) The co-immunohistochemical staining of BrdU (Green) and DCX (Red) (B) and bar graph (E-G) in hippocampus DG region showing the effects of thioperamide and H89 on DCX- 
(E) and BrdU/DCX (F, G)-positive newborn cells in DG in LPS treated mice. Scale bar: $100 \mu \mathrm{m}$. $(\mathrm{C}, \mathrm{H}, \mathrm{I})$ The co-immunohistochemical staining of BrdU (Red) and NeuN (Green) (C) and bar graph $(\mathrm{H}, \mathrm{I})$ in hippocampus DG region showing the effects of thioperamide and $\mathrm{H} 89$ on BrdU/DCX-positive newborn cells $(H, I)$ in $D G$ in LPS treated mice. $n=5$ per group. ${ }^{*} P<0.05, * \star P<0.01, * \star * P<0.001$. Mean $\pm S E M$. Oneway ANOVA followed by Tukey's post hoc test.

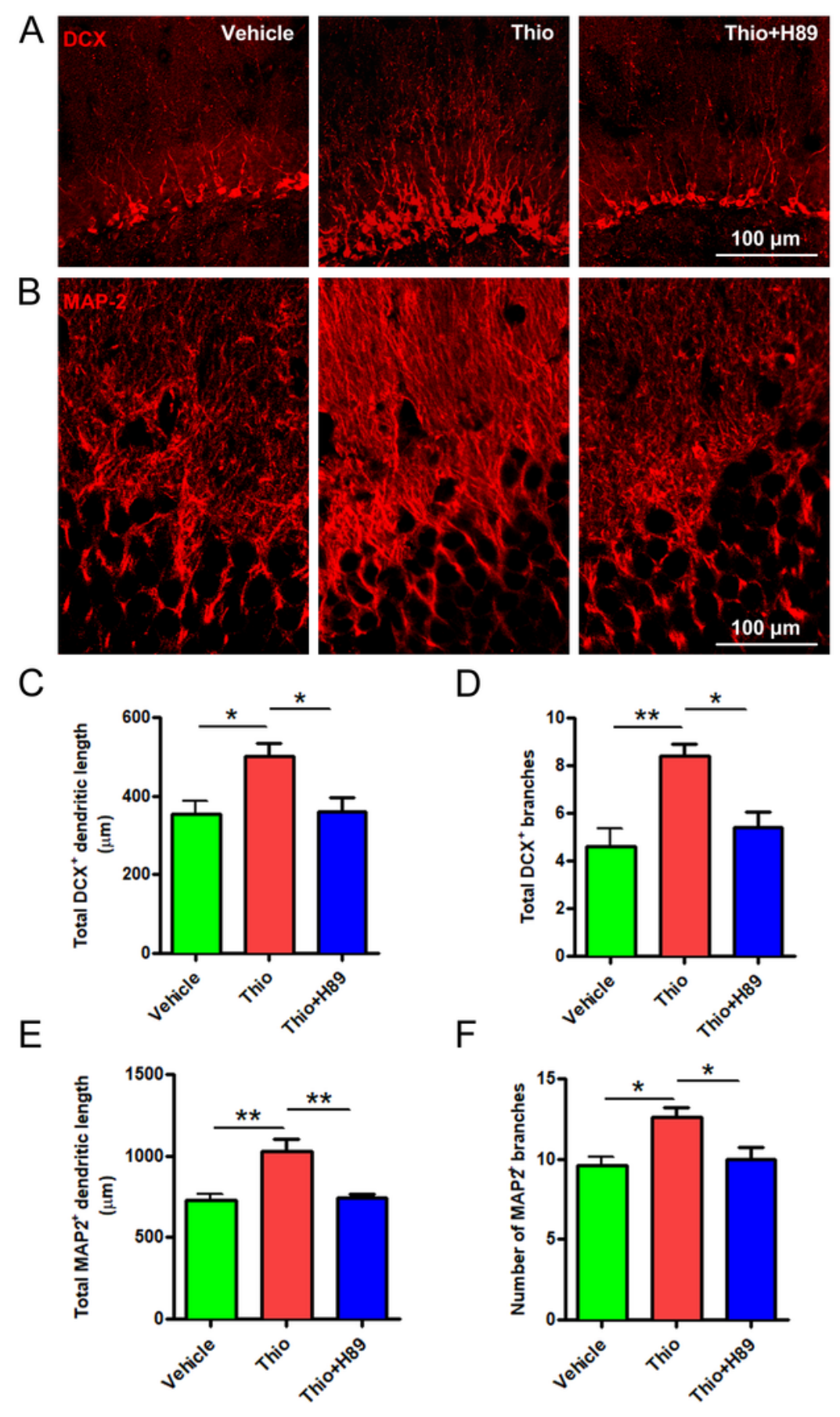

Figure 7 
H89 reverses the effect of thioperamide on dendritic complexity in LPS-treated mice. (A, B) The immunohistochemical staining showing the effects of thioperamide and H89 on morphology of DCXpositive immature neurons (red) (A) and MAP-2-positive mature neurons (red) (B) in LPS treated mice. Scale bar: $100 \mu \mathrm{m}$. (C-F) The bar graph indicated the effects of thioperamide and $\mathrm{H} 89$ on the total dendritic length $(C, E)$ and total branches $(D, F)$ of DCX-positive immature neurons $(C, D)$ and MAP-2positive mature neurons $(E, F)$ in LPS treated mice. $n=5$ per group. ${ }^{*} P<0.05,{ }^{*} P<0.01$. Mean $\pm S E M$. One-way ANOVA followed by Tukey's post hoc test.

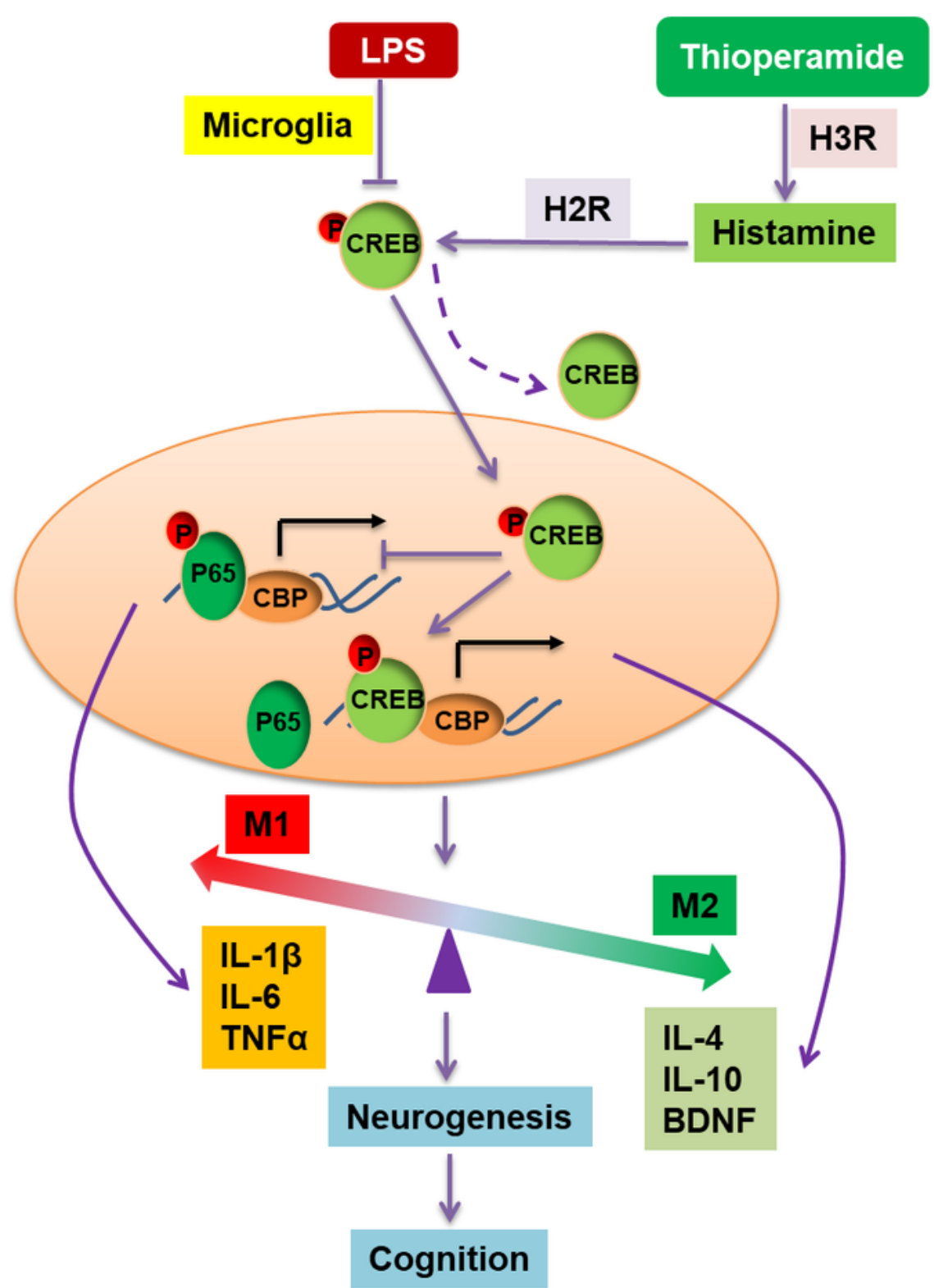




\section{Figure 8}

A proposed model for the neuroprotective effects of thioperamide against LPS induced neuroinflammation. Inhibition of $\mathrm{H} 3 \mathrm{R}$ by thioperamide promotes release of histamine, then activates $\mathrm{H} 2 \mathrm{R}$ and its downstream CREB signaling, upregulates anti-inflammatory cytokines from M2 microglia and downregulates pro-inflammatory cytokines from M1 microglia, and ultimately enhances neurogenesis and improves cognitive function. 